\title{
Evaluation of a near-global eddy-resolving ocean model
}

\author{
P. R. Oke, D. A. Griffin, A. Schiller, R. J. Matear, R. Fiedler, J. Mansbridge, A. Lenton, M. Cahill, M. A. Chamberlain, \\ and K. Ridgway
}

Centre for Australian Weather and Climate Research, CSIRO Marine and Atmospheric Research, G.P.O. Box 1538, Hobart TAS 7001, Australia

Correspondence to: P. R. Oke (peter.oke@csiro.au)

Received: 26 November 2012 - Published in Geosci. Model Dev. Discuss.: 18 December 2012

Revised: 27 March 2013 - Accepted: 12 April 2013 - Published: 3 May 2013

\begin{abstract}
Analysis of the variability of the last 18 yr (19932012) of a 32 yr run of a new near-global, eddy-resolving ocean general circulation model coupled with biogeochemistry is presented. Comparisons between modelled and observed mean sea level (MSL), mixed layer depth (MLD), sea level anomaly (SLA), sea surface temperature (SST), and chlorophyll $a$ indicate that the model variability is realistic. We find some systematic errors in the modelled MLD, with the model generally deeper than observations, which results in errors in the chlorophyll $a$, owing to the strong biophysical coupling. We evaluate several other metrics in the model, including the zonally averaged seasonal cycle of SST, meridional overturning, volume transports through key straits and passages, zonally averaged temperature and salinity, and El Niño-related SST indices. We find that the modelled seasonal cycle in SST is $0.5-1.5^{\circ} \mathrm{C}$ weaker than observed; volume transports of the Antarctic Circumpolar Current, the East Australian Current, and Indonesian Throughflow are in good agreement with observational estimates; and the correlation between the modelled and observed NINO SST indices exceeds 0.91. Most aspects of the model circulation are realistic. We conclude that the model output is suitable for broader analysis to better understand upper ocean dynamics and ocean variability at mid- and low latitudes. The new model is intended to underpin a future version of Australia's operational short-range ocean forecasting system.
\end{abstract}

\section{Introduction}

The purpose of this paper is to describe and assess a new near-global eddy-resolving ocean model, developed under Bluelink - a partnership between CSIRO, the Bureau of
Meteorology (BoM), and the Royal Australian Navy. The development of the new model - called the Ocean Forecasting Australian Model, version 3 (OFAM3) - is the first step in the development of a new, operational short-range ocean forecast system that will deliver daily forecasts of mesoscale circulation at mid- and low latitudes. This development builds on the success of Bluelink, and is intended to ultimately expand the scope of Australia's operational, short-range ocean forecast system (Brassington et al., 2007, www.bom.gov.au/ oceanography/forecasts/) from just the Australasian region to most of the globe, and from forecasts of the circulation to include forecasts of the biogeochemistry. Bluelink is Australia's main contribution to the Global Ocean Data Assimilation Experiment (GODAE; Smith, 2000), and its successor GODAE OceanView (www.godae-oceanview.org).

The Bluelink ocean model has been developed over many years. The first and second versions of OFAM (OFAM1 and OFAM2) were eddy-resolving in the $90^{\circ}$ sector centred on Australia and south of about $20^{\circ} \mathrm{N}$. The latest version of OFAM (OFAM3) is a major improvement over previous versions, with the eddy-resolving region being extended to all longitudes and between $75^{\circ} \mathrm{S}-75^{\circ} \mathrm{N}$, the addition of biogeochemistry and improvements to model parameterisations and forcing. Results from OFAM1 were first described by Oke et al. (2005), demonstrating that when constrained by data assimilation, OFAM produces reanalysed fields that were mostly in good agreement with with-held observations. Oke and Schiller (2007) described a series of observing system experiments using OFAM2, showing that all of the main components of the global ocean observing system are important for constraining an eddy-resolving ocean model. Oke et al. (2008) presented results using OFAM2 to show that when constrained by data assimilation, their 
model reproduced the variability around Australia with sea level anomaly (SLA) errors of $6-12 \mathrm{~cm}$ and sea surface temperature (SST) errors of $0.5-0.9^{\circ} \mathrm{C}$. Schiller et al. (2008) used results from the data assimilating version of OFAM2 to quantify the seasonal and interannual variability of the major currents in the Australian region and the Indonesian Throughflow (ITF). Using the same model, Schiller et al. (2010) showed that the deep-reaching sub-surface intraseasonal variability in the eastern Indian Ocean and the ITF is closely linked with equatorial wind stress anomalies in the central Indian Ocean. Other applications of previous versions of OFAM include an investigation of a series of coral bleaching events in the Great Barrier Reef (Schiller et al., 2009), an analysis of eddy dynamics in the Tasman Sea (Oke and Griffin, 2011), an analysis of fronts in the Southern Ocean (Langlais et al., 2010), an investigation of the seasonality of chlorophyll $a$ in anti-cyclonic eddies off Western Australia (Dietze et al., 2009), and a climate downscaling (Sun et al., 2012). The latest application of OFAM2 was for ocean reanalysis - called the Bluelink ReANalysis, version 3 (BRAN3; Oke et al., 2013) - spanning 1/1993-9/2012, where it was shown that BRAN3 outperforms the previous reanalysis (BRAN2), but required significantly less adjustment by the data assimilation system and is therefore more dynamically consistent. An operational version of OFAM2 is run at the Bureau of Meteorology (Brassington et al., 2007, www.bom.gov.au/oceanography/forecasts/). To date, the applications that depend on the current operational short-range ocean forecast system in Australia have been focussed on the ocean around Australia.

The details of the model configuration are described in Sect. 2. An evaluation of the last $18 \mathrm{yr}$ of a $32 \mathrm{yr}$ model run is presented in Sect. 3, followed by a summary and conclusions in Sect. 4. A comprehensive description of the technical details of the model configuration is given in Appendices A and $\mathrm{B}$.

\section{Model configuration}

OFAM3 is a near-global, eddy-resolving, $z^{*}$ configuration of version 4p1 of the Modular Ocean Model (Griffies, 2009), developed principally for the purpose of hindcasting and forecasting upper ocean conditions in non-polar regions. The key features of the configuration of OFAM3 are described here, and a comprehensive technical description of OFAM3, including model parameterisations, initial conditions, and forcing, is given in Appendix A. The model grid has $1 / 10^{\circ}$ grid spacing for all longitudes and between $75^{\circ} \mathrm{S}$ and $75^{\circ} \mathrm{N}$, with $5 \mathrm{~m}$ vertical resolution down to $40 \mathrm{~m}$ depth and $10 \mathrm{~m}$ vertical resolution to $200 \mathrm{~m}$ depth.

OFAM3 uses the vertical mixing scheme described by Chen et al. (1994), and a biharmonic Smagorinsky viscosity scheme described by Griffies and Hallberg (2000) OFAM3 is forced with $1.5^{\circ}$-resolution, 3-hourly surface heat, freshwater, and momentum fluxes from ERA-Interim (Dee and Uppala, 2009). Surface temperature is restored to monthly averaged observations with a nominal restoring timescale of 10 days. Similarly, surface salinity is restored to monthly averaged climatology with a restoring timescale of 30 days. The surface restoring term for temperature scales like $\rho c_{p} \Delta z_{\text {surf }} / \Delta t \sim 23 \mathrm{~W} \mathrm{~m}^{-2} \mathrm{~K}^{-1}\left(\rho c_{p} \sim\right.$ $4 \times 10^{6} \mathrm{~J} \mathrm{~K}^{-1} \mathrm{~m}^{-3} ; \Delta z_{\text {surf }}=5 \mathrm{~m}$ is vertical grid spacing at the surface; and $\Delta t=10 \times 86400 \mathrm{~s}$, is the nominal restoring timescale). Each time step the impact of this restoring term is quickly spread over the surface mixed layer, "diluting" the impact of the restoring term by the ratio of $\Delta z_{\text {surf }} /$ MLD (where MLD is the mixed layer depth). So, if the MLD is $50 \mathrm{~m}$ (10 times $\Delta z_{\text {surf }}$ ), then the effective restoring timescale is ten times greater than the prescribed timescale.

The model was initialised at rest, with zero sea level, and with potential temperature and salinity from climatology, then integrated for $32 \mathrm{yr}$. The first $14 \mathrm{yr}$ is the spin-up period, and the last $18 \mathrm{yr}$, spanning the period 1993-2010, are analysed in this study.

OFAM3 includes a BGC cycling model, called the Whole Ocean Model with Biogeochemistry and Trophic-dynamics (WOMBAT). A comprehensive description of WOMBAT, including parameterisations, initial conditions and forcing, is given in Appendix B. Briefly, WOMBAT is a threedimensional NPZD (nutrient-phytoplankton-zooplanktondetritus) model described by Kidston et al. (2011), with the addition of the iron, oxygen, and carbon cycles. The iron, oxygen, and carbon cycles are linked to the phosphate uptake and remineralisation through a constant Redfield ratio, and the formation of calcium carbonate is a constant fraction of organic carbon production. The atmospheric iron deposition is set by a seasonal climatology (Mongin et al., 2011); and the air-sea exchange of carbon dioxide is a function of wind speed (Wanninkhof, 1992) and climatological sea ice concentration (Matear and Lenton, 2008). Phytoplankton growth is limited by light, phosphate and iron, with the minimum of these three terms limiting growth. Initial conditions for the biophysical fields are derived from an observation-based climatology. The focus of this paper is on upper ocean variability, which reaches quasi-steady state in about $2 \mathrm{yr}$ (Matear, 1995), while the deep ocean takes much longer to reach steady state (Matear and Hirst, 2003).

\section{Model evaluation}

\subsection{Mean sea level}

We compare the modelled mean sea level (MSL), averaged over the last $18 \mathrm{yr}$ of the model run, with an observationbased estimate of the MSL from version 1.1 of the CNESCLS09 (Rio et al., 2009) in Fig. 1. The CNES-CLS09 field is computed for the time period 1993-1999, and is relative to a geoid computed from $4.5 \mathrm{yr}$ of GRACE data. Both the 
(a)
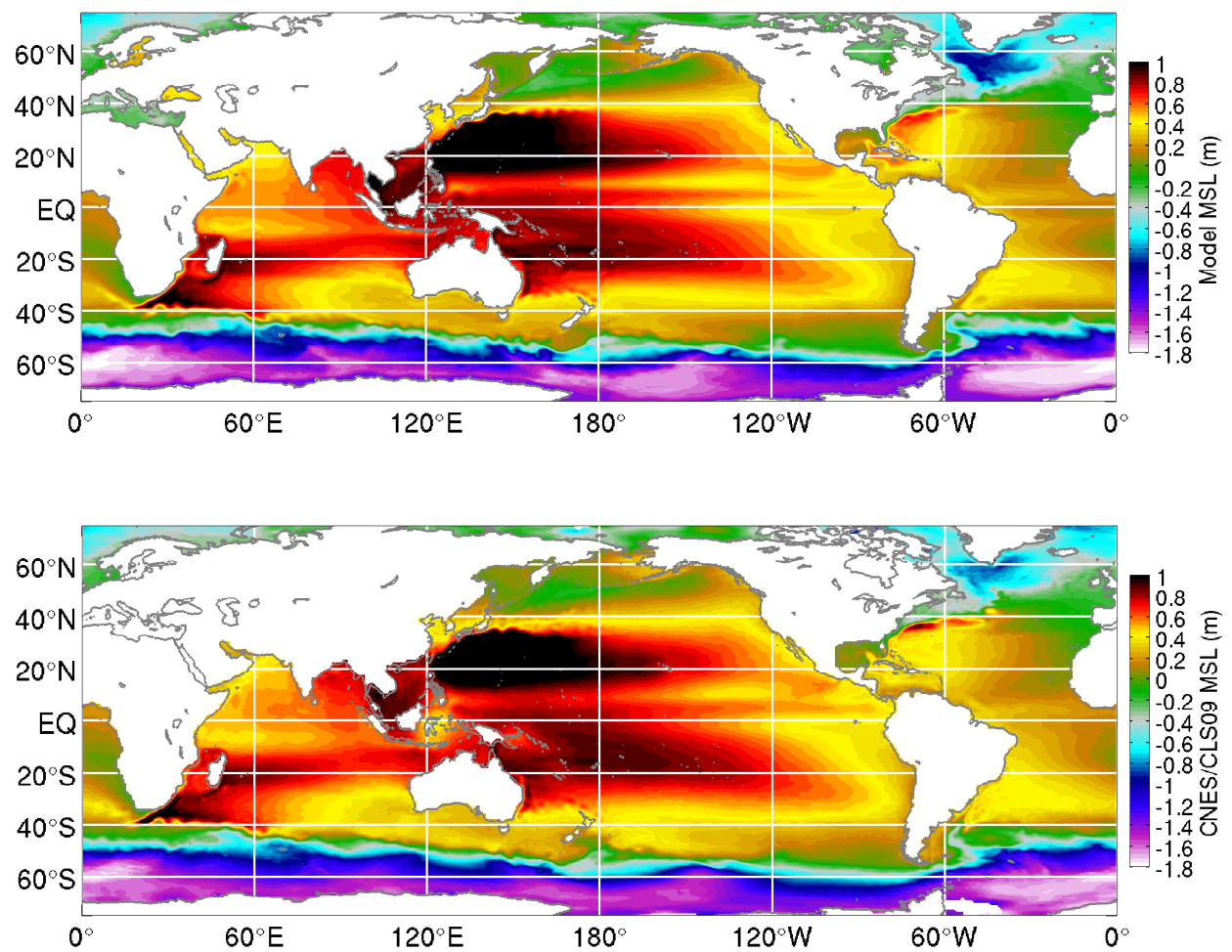

(b)

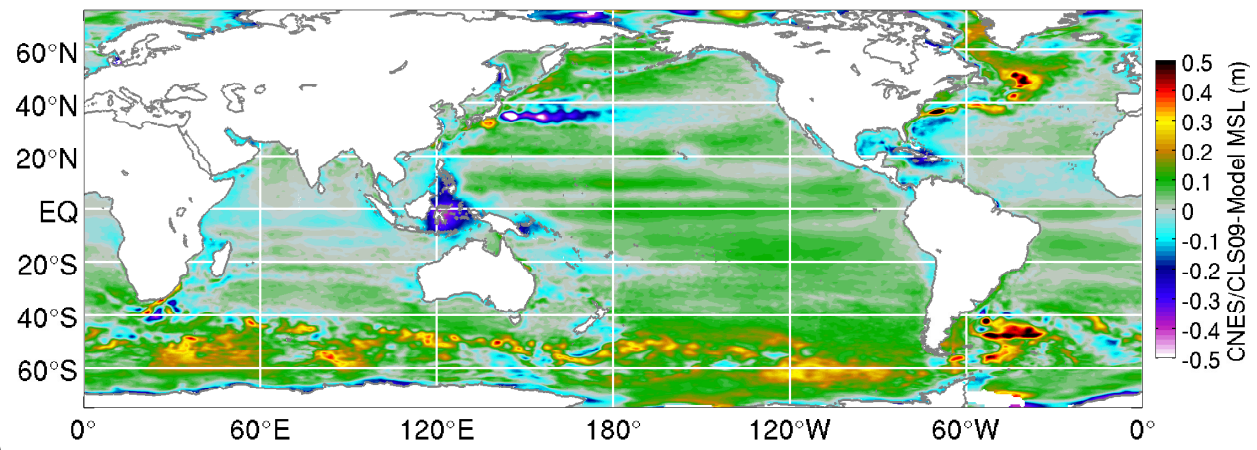

Fig. 1. Comparison of the (a) mean sea level from the model, (b) the mean dynamic topography from CNES-CLS09 V1.1, and (c) the difference between the CNES-CLS09 and the model MSL field.

modelled and observed estimate of MSL are similar, with the key basin-scale gyres clearly evident. There are a few regions where there are systematic differences between the modelled and observed MSL estimates. For example, the CNESCLS09 estimate over the Indonesian seas, centred around $120^{\circ} \mathrm{E}$, is up to $0.4 \mathrm{~m}$ less than the model estimate. The modelled Kuroshio extension appears to track farther north than the observations indicate, showing up as a zonal band of negative MSL difference in Fig. 1c. The meridional gradients of the MSL associated with the Gulf Stream are sharper in the observations, with a stronger meridional gradient along the path of the Gulf Stream extension. This shows up as a quasizonal band of positive MSL difference in Fig. 1c. The path of the Antarctic Circumpolar Current (ACC), denoted here by MSL of between about $-0.8 \mathrm{~m}$ and $-0.2 \mathrm{~m}$ (dark blue to green), includes more structure in the model than the observations. A systematic difference is evident in the BrazilMalvinas Confluence (BMC), where the observational estimate of MSL is about $0.5 \mathrm{~m}$ higher than in the model. We interpret this as an indication that the complicated circulation associated with the BMC may be misplaced in the model. The modelled MSL south of Greenland is lower than the observations by about $0.4 \mathrm{~m}$. This may be a consequence of the approximations used in this model to represent variability associated with the Arctic Ocean (see Appendix A). 
(a)
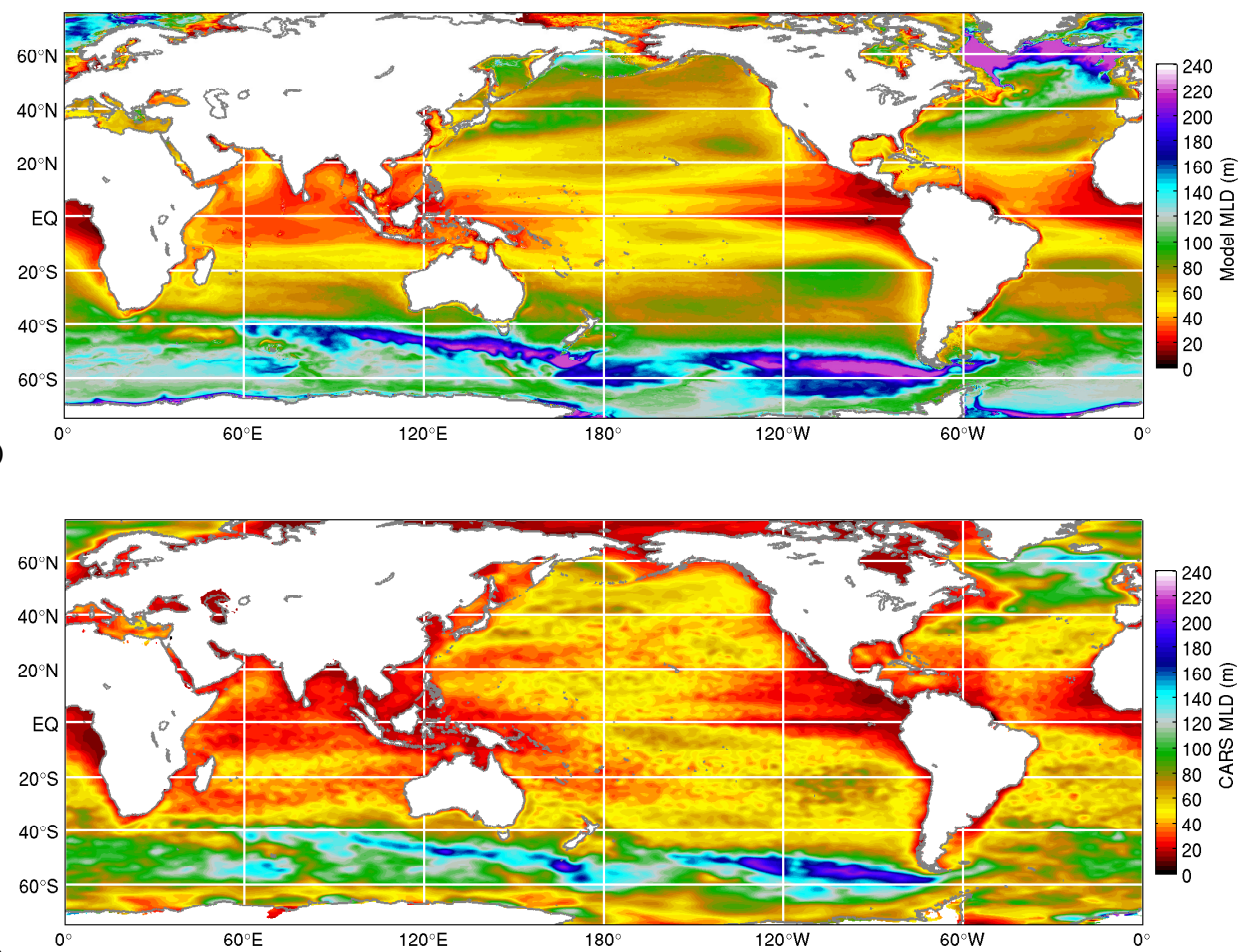

(b)

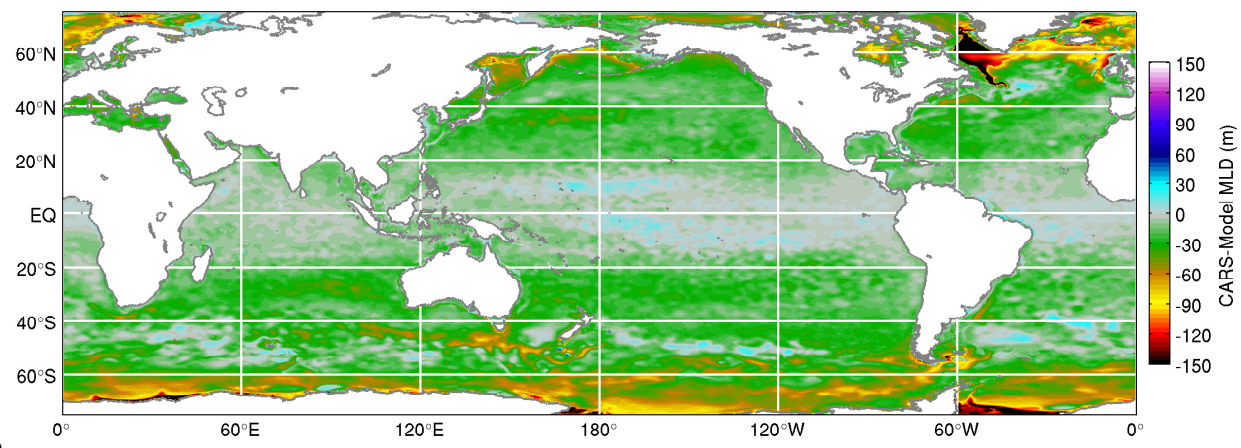

Fig. 2. Comparison of the time-averaged MLD (m) from the (a) model, (b) CARS (Ridgway and Dunn, 2003), and (c) the difference between the CARS and model MLD field. The model MLD is calculated from daily means using the MLD definition described by de Boyer Montegut et al. (2004).

\subsection{Mixed Layer Depth}

We compare the modelled mean ocean surface Mixed Layer Depth (MLD), averaged over the last 18 yr of the model run, with an observation-based estimate of the MLD from the CSIRO Atlas of Regional Seas (CARS; Ridgway and Dunn, 2003) in Fig. 2. The definition of the MLD that is used here is based on de Boyer Montegut et al. (2004). Specifically, for each grid point in the model we identify the depth over which the potential density increases by $0.3 \mathrm{~kg} \mathrm{~m}^{-3}$ and temperature decreases by $0.2^{\circ} \mathrm{C}$ from the surface value. The time-averaged MLD field shown in Fig. 2 is the maximum of the MLD estimates obtained using these two criteria. The temperature-based criterion is used in regions where there are compensating layers (de Boyer Montegut et al., 2004). The modelled and observed time-averaged MLD fields show similar spatial patterns, with good correspondence between regions of shallow and deep mixed layers. The anomaly correlation between the time-averaged modelled and observed MLD is 0.86 . Both the modelled and observed MLD fields show shallow MLDs at low latitude. The mean and rootmean-square difference (RMSD) between the observed and modelled MLD (Fig. 2c) within $15^{\circ}$ of the Equator are $-3.9 \mathrm{~m}$ and $6.8 \mathrm{~m}$, respectively; with the model showing deeper MLDs than the observations. Both the model and observations have deep mixed layers along the path of the ACC 

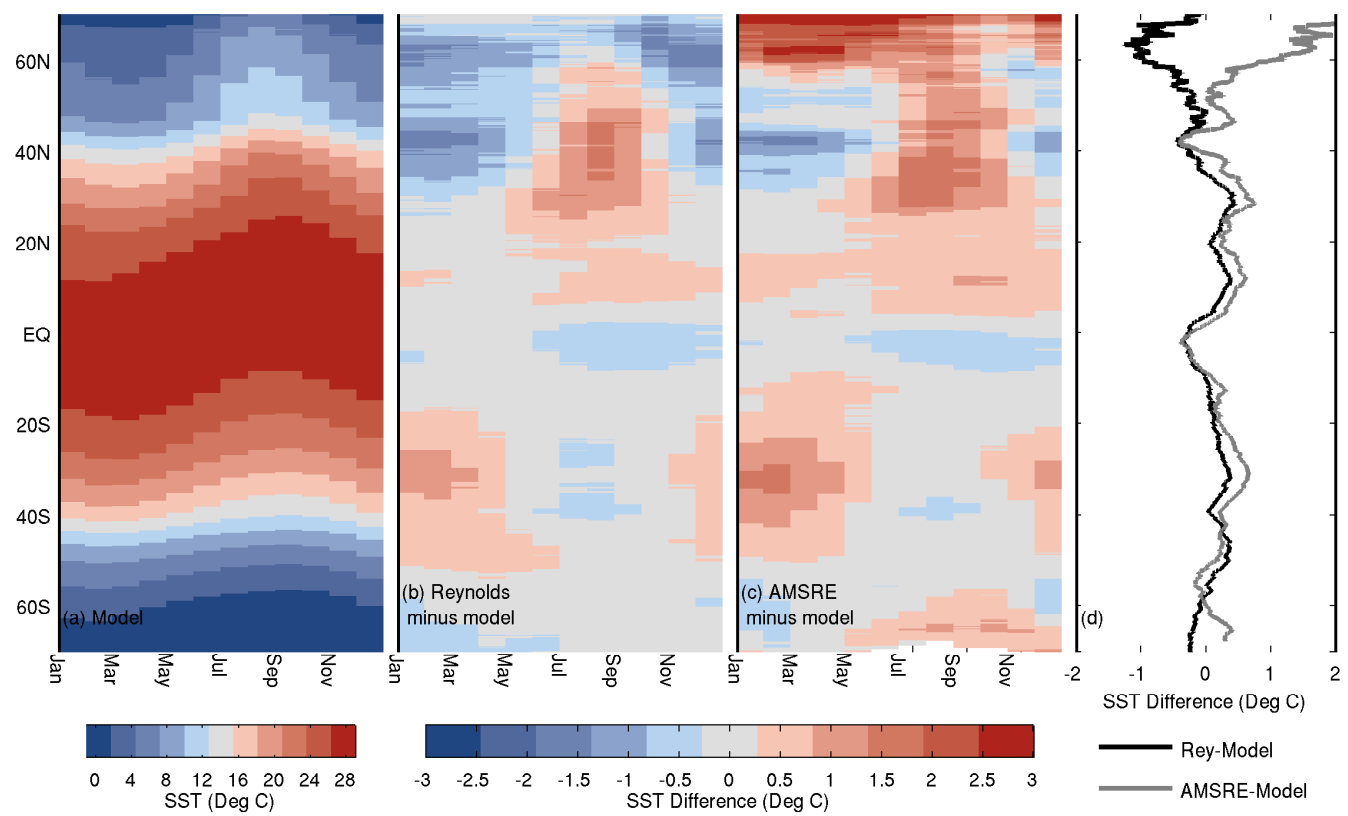

Fig. 3. (a) Seasonal climatology of zonally averaged modelled SST, the zonal average of the difference between modelled and observed SST seasonal climatology using (b) Reynolds SST and (c) AMSR-E SST, and (d) the time-averaged and zonally averaged difference between observed and modelled SST.

- particularly south of Australia and New Zealand, and between about $140^{\circ} \mathrm{W}$ and $60^{\circ} \mathrm{W}$. In the locations where the model MLD exceeds $180 \mathrm{~m}$ in the Southern Hemisphere, the average model MLD is almost $60 \mathrm{~m}$ deeper than the CARS MLD. Similarly, at high latitudes (north of $50^{\circ} \mathrm{N}$ and south of $60^{\circ} \mathrm{S}$ ) the mean and RMSD between the observed and modelled MLD are $-48.8 \mathrm{~m}$ and $58.5 \mathrm{~m}$, respectively - again with the model having deeper MLDs than observed. In general, in regions of strong convection (e.g. Weddell, Ross and Labrador seas, and south-eastern Pacific) the model mixed layers are too deep. We suspect that this mismatch between the model and observations is largely due to limitations of the model (e.g. with no coupled sea ice model) - but we note that in situ ocean and atmospheric observations in those regions are scarce, with fewer observations in winter - so the observational estimates will contain some error, and possibly some seasonal bias (e.g. not properly representing the deep winter mixed layer). This aspect of OFAM3 has been analysed in detail by Schiller and Ridgway (2013).

\subsection{SST seasonal cycle}

Here, we compare the seasonal cycle of the modelled SST with gridded $1 / 4^{\circ}$-resolution satellite observations from AMSR-E (www.ssmi.com) and Reynolds et al. (2007). The zonally averaged mean seasonal cycle from the model is shown in Fig. 3a, along with the difference between the modelled and observed seasonal cycle in Fig. 3b-c, and the time-averaged, zonally averaged differences in Fig. 3d. The AMSR-E fields are 7-day averages and are based on data for the period 1/2003-12/2010; and the model and Reynolds fields are for the entire $18 \mathrm{yr}$ model run (note that we restore OFAM3 to Reynolds SST). These comparisons demonstrate the seasonal cycle in the model is generally too weak. In each hemisphere at mid-latitude, the zonally averaged SST is $0.5-$ $1.5^{\circ} \mathrm{C}$ too cold in summer, and $0.5-1.0^{\circ} \mathrm{C}$ too warm in winter. North of about $55^{\circ} \mathrm{N}$, the AMSR-E SST is up to $2.5^{\circ} \mathrm{C}$ warmer than the model, and Reynolds SST is over $1.5^{\circ}$ colder than the model. This indicates that north of $55^{\circ} \mathrm{N}$, the observations are in disagreement. For most latitudes, the timeaveraged, zonally averaged SST in the model is within $0.5^{\circ} \mathrm{C}$ of observations.

Recall that the model SST is restored to monthly Reynolds SST with a nominal restoring timescale of 10 days. We argue, in Sect. 2, that the heat flux associated with the SST restoring is likely to be relatively weak. This is quantified in Table 1 , where we show the time mean and standard deviation of the globally averaged components of the heat flux - including the restoring term. This shows that the fluxes associated with the restoring term are small compared to the individual components of the prescribed flux. We suspect that the use of a bulk formula for the heat flux will result in stronger sensible and latent heat fluxes (since they both have a feedback term that depends on the difference between the model SST and the air temperature) and may result in better agreement with observations. This aspect of OFAM will be investigated in future versions. 
Table 1. Time mean plus/minus the standard deviation $\left(\mathrm{W} \mathrm{m}^{-2}\right)$ of the area-averaged surface heat flux components for the full model domain (column 2), and for each of the NINO regions (columns 3-6) presented in Fig. 6.

\begin{tabular}{lccccc}
\hline Heat flux component & Global & NINO1.2 & NINO3 & NINO4 & NINO3.4 \\
\hline Total & $4.5 \pm 14.4$ & $63.0 \pm 40.1$ & $70.8 \pm 28.2$ & $32.5 \pm 21.9$ & $55.6 \pm 27.9$ \\
Short wave & $178.4 \pm 16.5$ & $233.6 \pm 28.4$ & $244.5 \pm 14.4$ & $234.3 \pm 21.0$ & $247.9 \pm 17.8$ \\
Long wave & $-61.3 \pm 1.3$ & $-49.9 \pm 8.5$ & $-61.5 \pm 3.0$ & $-63.9 \pm 4.1$ & $-64.5 \pm 3.7$ \\
Latent & $-104.0 \pm 2.4$ & $-76.4 \pm 16.3$ & $-97.8 \pm 18.6$ & $-130.5 \pm 13.7$ & $-118.0 \pm 19.4$ \\
Sensible & $-13.5 \pm 0.8$ & $-8.4 \pm 3.2$ & $-6.5 \pm 1.3$ & $-9.5 \pm 2.0$ & $-7.0 \pm 1.5$ \\
Restoring & $4.9 \pm 1.5$ & $-35.9 \pm 16.1$ & $-7.9 \pm 10.2$ & $2.1 \pm 6.6$ & $-2.8 \pm 7.6$ \\
\hline
\end{tabular}

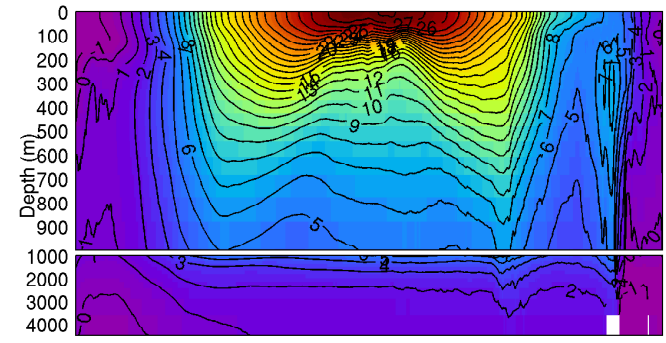

(a)

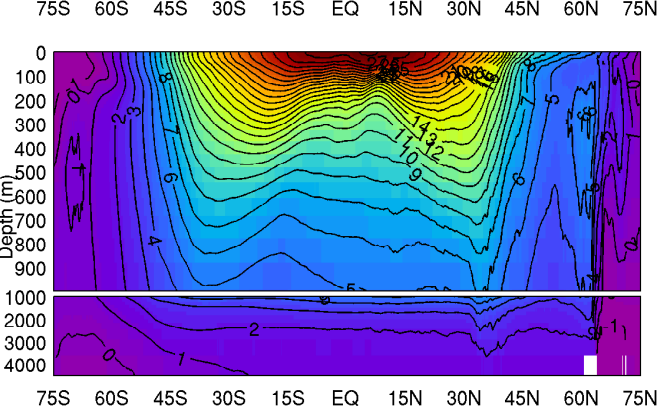

(c)

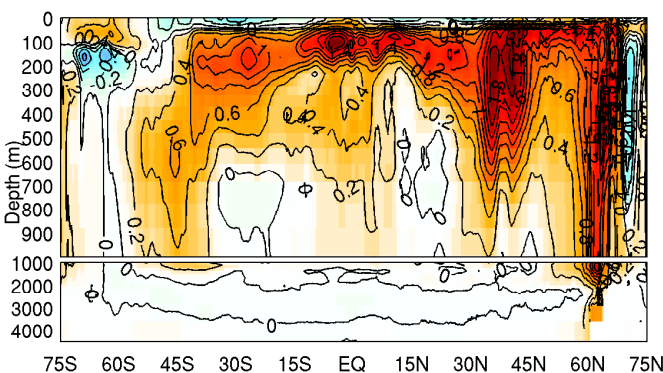

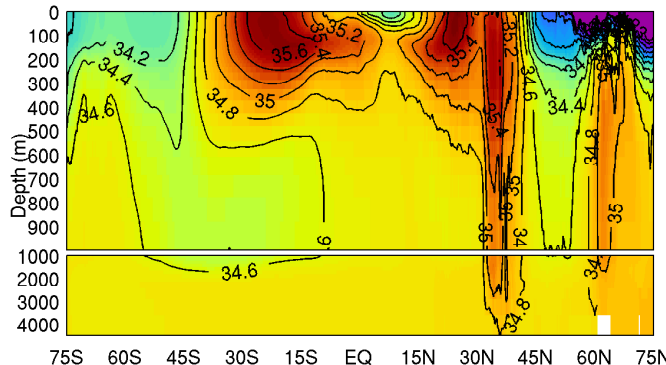

(b)
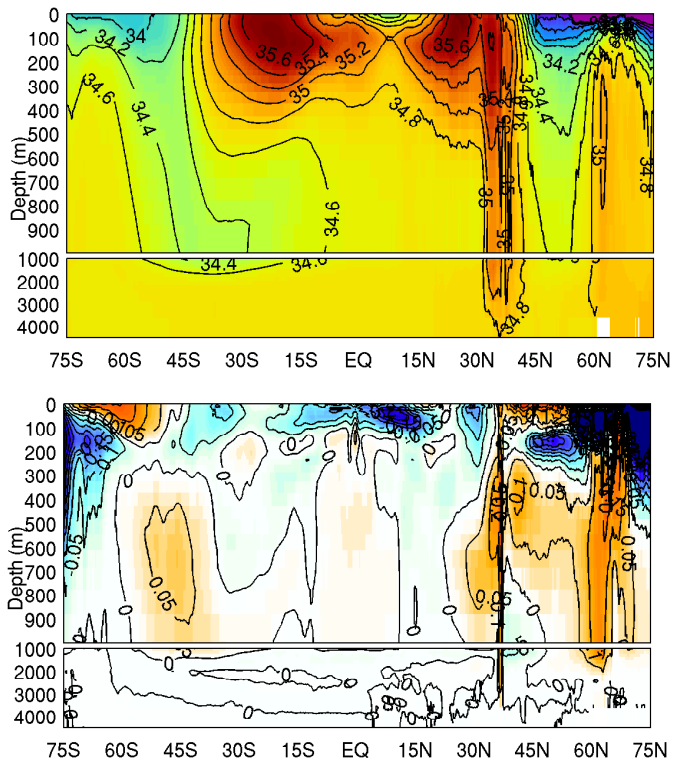

Fig. 4. (a, b) Modelled, (c, d) observed, and (e, f) modelled minus observed time and zonal mean (a, c, e) temperature and (b, d, f) salinity. The contour intervals for temperature are $1{ }^{\circ} \mathrm{C}$ in $(\mathbf{a}, \mathbf{c}, \mathbf{b})$ and $0.2^{\circ} \mathrm{C}$ in (e). The contour interval for salinity is $0.2 \mathrm{psu}$ in $(\mathbf{b}, \mathbf{d})$ and $0.05 \mathrm{psu}$ in (f).

\subsection{Zonally averaged fields}

The time mean and zonal average of modelled potential temperature and salinity are shown in Fig. 4, along with their differences from climatology. The time mean and zonal average modelled potential temperature field (Fig. 4a) shows the expected broad-scale features, with warm water at shallow, low latitudes, and cold waters over all depths at high latitudes. The time mean and zonal average modelled salinity (Fig. 4b) includes a representation of the expected features, including Antarctic Intermediate water, with salinity of 34.6 psu penetrating to about $1000 \mathrm{~m}$ depth between $60-15^{\circ} \mathrm{S}$, high salinity (up to $35.2 \mathrm{psu}$ ) over the top $300 \mathrm{~m}$ centred around $25^{\circ} \mathrm{S}$, a salinity minimum of $34.1 \mathrm{psu}$ at about $5^{\circ} \mathrm{N}$ associated with the strong precipitation in the inter-tropical convergence zone, high-salinity water associated with the Mediterranean Sea at about $35^{\circ} \mathrm{N}$, low-salinity water over the top $200 \mathrm{~m}$ north of $45^{\circ} \mathrm{N}$ associated with the meltwater from the Arctic 

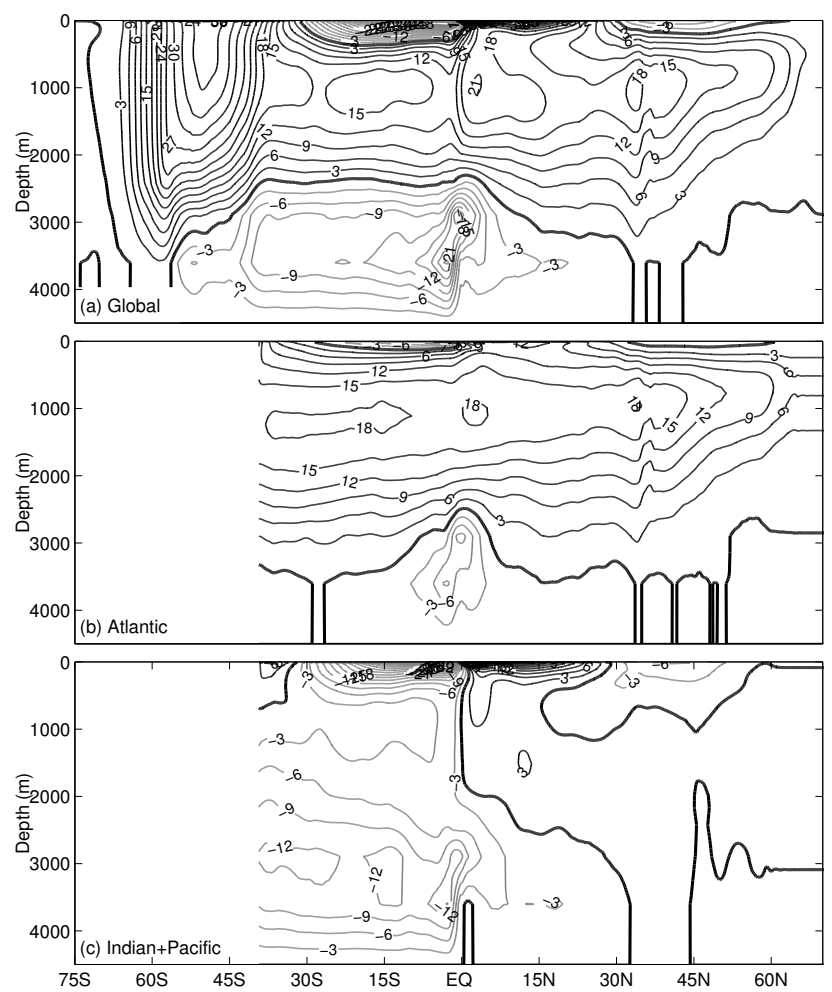

Fig. 5. Time mean, zonally averaged meridional overturning stream function (Sv) for the (a) entire globe, (b) Atlantic basin, and (c) Indian+Pacific basins. Solid contours are positive (clockwise), grey contours negative (anticlockwise), and bold contours zero. For clarity, fields have been averaged to eliminate features that are shorter than 1 degree.

(although only represented through restoring along the northern boundary in this model), and high-salinity (35.2 psu) water below $300 \mathrm{~m}$ depth north of $60^{\circ} \mathrm{N}$ associated with the formation of North Atlantic Deep Water. All of these features are clearly evident in climatology.

The difference field for temperature (Fig. 4e) indicates that between about 50 and $200 \mathrm{~m}$ depth, the model temperature is too high, by up to $2{ }^{\circ} \mathrm{C}$. The greatest temperature differences are evident at around $35^{\circ} \mathrm{N}$, corresponding to the Mediterranean Sea, and around $65^{\circ} \mathrm{N}$. The difference field for salinity (Fig. 4f) indicates that the model is about $0.2-0.4$ psu too fresh off Antarctica, between 50 and $1000 \mathrm{~m}$ depth. Conversely, the model is up to 0.2 psu too saline between 0$100 \mathrm{~m}$ depth at around $50^{\circ} \mathrm{S}$, and $0.1-0.3 \mathrm{psu}$ too fresh within 20 degrees of the Equator in the upper $100 \mathrm{~m}$ of the water column. The model is up to $1.5 \mathrm{psu}$ too fresh north of $60^{\circ} \mathrm{N}$ between 100-200 m depth because of the errors associated with the crude salinity restoring at the northern boundary that is intended to provide some representation of the properties of the flow from the Arctic basin. The model is about 0.2 psu too saline near the surface north of $40^{\circ} \mathrm{N}$ and is about 0.1 psu too saline between 100 and $1500 \mathrm{~m}$ depth between 50 and $70^{\circ} \mathrm{N}$.

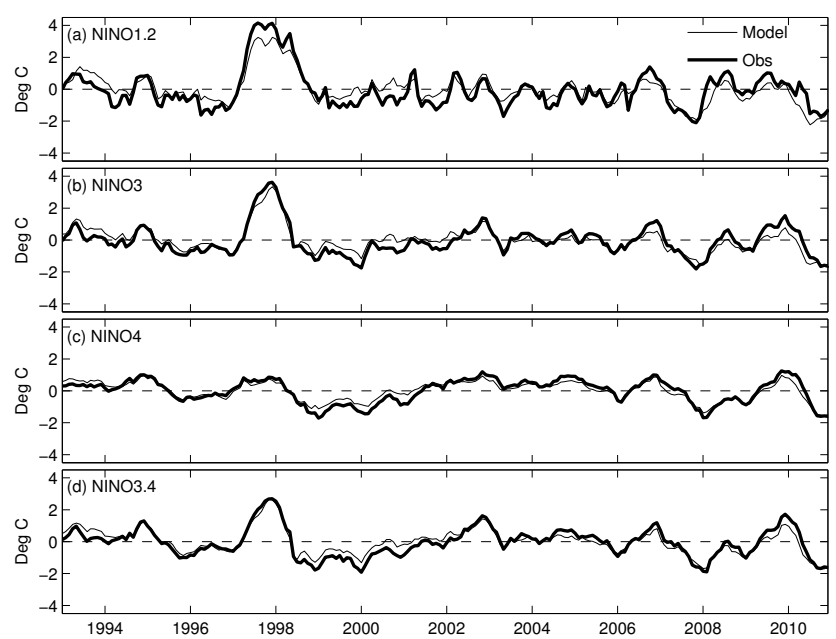

Fig. 6. Time series of the (a) NINO1.2, (b) NINO3, (c) NINO4, and (d) NINO3.4 SST anomalies from observations (OSTIAv2) and the model (OFAM3).

The differences between the model and climatology for both temperature and salinity are small below $2000 \mathrm{~m}$ depth owing to the restoring to climatology (see Appendix A).

The time mean zonally averaged meridional overturning stream function is shown in Fig. 5 for a global mean, and a zonal mean across the Atlantic basin, and the Indian+Pacific basins. The meridional overturning circulation (MOC) in the Atlantic basin peaks to $18.9 \mathrm{~Sv}$ at $40^{\circ} \mathrm{N}$; and the crossequatorial transport is $18.5 \mathrm{~Sv}$. The globally averaged MOC shows that the maximum MOC in the Deacon cell is $39 \mathrm{~Sv}$. These results are comparable to other model-based estimates (e.g. Maltrud and McClean, 2005; Kohl and Stammer, 2007; Doos et al., 2008), and to observational estimates in the North Atlantic (e.g. Cunningham et al., 2007).

\subsection{El Niño-related indices}

Time series of the observed and modelled NINO1.2, NINO3, NINO4, and NINO3.4 anomalies are shown in Fig. 6. The observed indices are based on monthly mean Reynolds SST (Reynolds et al., 2007). The biggest event in the time series is the large positive anomaly in NINO1.2, NINO3 and NINO3.4, corresponding to the 1997 El Niño. This event is well reproduced by the model, with the correct phase and amplitude. The agreement between the modelled and observed NINO1.2, 3, 4 and 3.4 anomalies is excellent, with a correlation of $0.91,0.96,0.96$, and 0.97 , respectively, and an RMSD of $0.56,0.38,0.26$, and $0.32{ }^{\circ} \mathrm{C}$, respectively.

We note that the modelled and observed estimates of the NINO indices shown in Fig. 6 are not independent. Recall that the model SST is restored to monthly mean observed SST to keep it relatively close to the observations. However, as we argue in Sect. 2, the impact of the restoring term on SST is weak. To quantify the degree to which the SST 


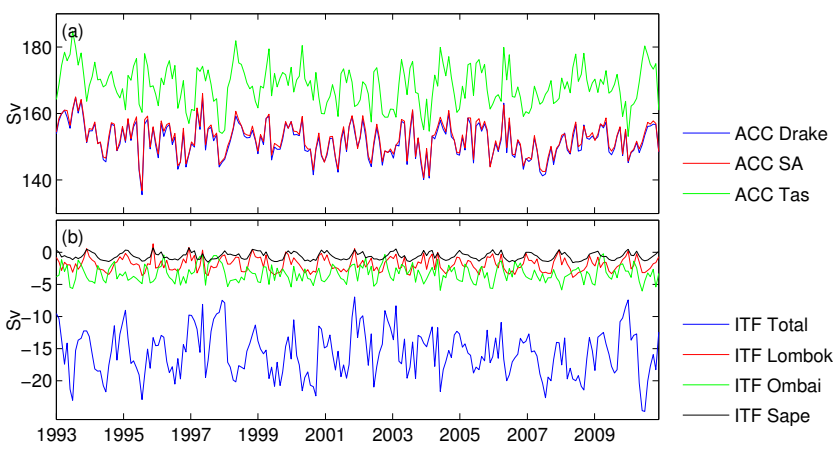

Fig. 7. Time series of the monthly averaged volume transport of the (a) ACC and (b) ITF, through various straits.

restoring influences the model solution, we show the mean and standard deviation of the area-averaged of the heat flux components for each of the NINO regions (Fig. 6) in Table 1. Specifically, we show the total, short-wave, long-wave, latent, and sensible heat flux, along with the restoring term, expressed as a heat flux. For both the NINO4 and NINO3.4 regions, the restoring term is the smallest of all of the heat flux terms. For the NINO1.2 and NINO3 regions, the restoring term is only larger than the sensible heat flux component. This indicates that the impact of restoring the model SST towards observed SST is small compared to the other components of the heat flux term - two orders of magnitude smaller than the largest term (short wave). We therefore conclude that most of the time variability shown in Fig. 6 is attributable to model dynamics - not the SST restoring. We also note that the nature of the restoring term is analogous to the sensible and latent heat flux components within a bulk heat flux formulation, where the model SST is effectively restored towards air temperature near the ocean surface. We plan to adopt a bulk formula in future versions of OFAM.

\subsection{Volume transports}

The time mean modelled volume transports through welldefined straits and passages are listed in Table 2, along with observation-based estimates (where available) for each region. In each case, the observational estimates are based on some assumptions, either about the governing dynamics (e.g. geostrophy), level of no motion, or from interpolation and extrapolation of discrete observations. The modelled ACC transport is between about $144 \mathrm{~Sv}$ and $176 \mathrm{~Sv}$. The time series of monthly averaged volume transports of the ACC through the Drake Passage, south of South Africa, and south of Tasmania are presented in Fig. 7a. This demonstrates that the ACC volume transports are free from any significant drift, and that the model transports are 10-15\% stronger than observed estimates in Drake Passage and south of Tasmania (Rintoul and Sokolov, 2001; Cunningham et al., 2003). We attribute the lack of drift in the ACC transports to the weak, deep-restoring of temperature and salinity to climatology. We find that without this deep restoring, the sub-surface properties drift significantly influencing the circulation over the entire water column. We retain the deep restoring in this model because it is developed with short-range ocean forecasting and upper-ocean mesoscale variability in mind - rather than climate scales.

The volume transport through the ITF passages includes observational estimates from the INSTANT program (Gordon et al., 2010). The INSTANT estimates are for a $3 \mathrm{yr}$ period, considerably shorter than the $18 \mathrm{yr}$ model averages. Given these differences, the modelled and observed estimates agree within a reasonable tolerance. The partitioning of the volume transport (normalised to 100) between Timor:Lombok: Ombai straits is $59: 15: 26$ in the model, in good agreement with the observed partitioning of 50 : $17: 33$. Note that the total ITF estimate is the transport between Indonesia and Australia at $114^{\circ} \mathrm{E}$, thereby capturing the transport between Timor and Australia. Times series of the monthly averaged volume transports of the ITF are presented in Fig. 7b. This shows that the modelled ITF transports are free from any significant drift.

A more detailed comparison of the model velocities with the INSTANT observations is presented in Fig. 8, showing time series of the along-strait velocities at Lombok and Ombai straits. At both Lombok and Ombai straits, there is very good correspondence between velocity fluctuations over the course of the $3 \mathrm{yr}$ INSTANT program. The correlation between the modelled and observed velocities exceeds $0.6(0.8)$ above $210 \mathrm{~m}(90 \mathrm{~m})$ depth at Lombok, and exceeds 0.6 above $1000 \mathrm{~m}$, and 0.8 between $200-400 \mathrm{~m}$ depth at Ombai. The observations show several reversals in the flow, with water flowing out of the Indian Ocean and into the Indonesian seas, which is well represented by the model. The strongest reversal is around mid-2004, with positive velocities in excess of $0.8 \mathrm{~m} \mathrm{~s}^{-1}$ over the upper $250 \mathrm{~m}$ at Lombok and $700 \mathrm{~m}$ at Ombai. The model shows good quantitative agreement during this major event. In general, the strength and vertical profile of the modelled velocities at Lombok Strait agree well with observations. However, at Ombai Strait, the model velocities are generally too weak and too shallow. The velocities at Ombai Strait show a sub-surface maximum for much of the INSTANT program. This feature of the observed velocities is also present in the model - though again, the model velocities tend to be too weak at depth.

The range of depths for which the model velocities are presented in Fig. 8 corresponds to the depths of the observations, and excludes the near-surface velocity. We have found that in many regions, the vertical velocity shear in OFAM3 near the surface is greater than expected. Through a series of sensitivity experiments, we have found this to be sensitive to the value of the maximum vertical viscosity (see Appendix A). We are currently undertaking a detailed assessment of the model's surface and near-surface velocity.

We compute the volume transport of the East Australian Current (EAC) between Brisbane and (just beyond) New 
Table 2. Comparison of volume transports in key straits and passages from the model and from observations. Where error bars were available, they are included below. The errors for the model estimates are standard deviations of monthly means. The EAC transports are based on geostrophic velocities along frequently repeated expendable bathythermograph (XBT) lines and are referenced to $2000 \mathrm{db}$; showing the mean and the maximum mean transport. The longitude of the maximum transport is also indicated.

\begin{tabular}{lrrl}
\hline & Modelled (Sv) & Observed (Sv) & Reference \\
\hline ACC & & & \\
$\quad$ Tasmania & $168.4 \pm 8.4$ & $147 \pm 10$ & Rintoul and Sokolov (2001) \\
$\quad$ Drake Passage & $151.9 \pm 7.5$ & $136.7 \pm 7.8$ & Cunningham et al. (2003) \\
$\quad$ South Africa & $152.6 \pm 8.1$ & - & \\
\hline ITF (Total, $\left.114^{\circ} \mathrm{E}\right)$ & $-15.7 \pm 4.8$ & 13.6 & Lee et al. (2010) \\
$\quad$ Timor Strait & $-7.6 \pm 1.7$ & -7.5 & Gordon et al. (2010) \\
$\quad$ Lombok Strait & $-1.9 \pm 1.4$ & -2.6 & Gordon et al. (2010) \\
$\quad$ Ombai Strait & $-3.4 \pm 1.9$ & -4.9 & Gordon et al. (2010) \\
$\quad$ Sape Strait & $-0.6 \pm 0.7$ & - & \\
\hline EAC mean & & & \\
$\quad$ Brisbane-New Caledonia** & $-8.6 \pm 8.6$ & $-9.6 \pm 5.4$ & - \\
$\quad$ Sydney-Wellington & $-6.8 \pm 5.6$ & $-10.7 \pm 5.6$ & - \\
EAC maximum & $-21.6 \pm 10.6$ & $-19.8 \pm 9.3$ & - \\
$\quad$ Brisbane (155.1 $\left.{ }^{\circ} \mathrm{E}\right)$ & $-16.2 \pm 19.6$ & $-17.2 \pm 17.6$ & - \\
$\quad$ Sydney (153.5 $\mathrm{E})$ & $23.7 \pm 2.2$ & 31.6 & RAPID-WATCH MOC \\
\hline Florida Current & $-19.1 \pm 8.0$ & -16.7 & van der Werf et al. (2010) \\
Mozambique Channel &
\end{tabular}

* Note that the "observational" estimate for the total ITF (Indonesian Throughflow) transport is based on the average of 14 data-assimilating ocean models (Lee et al., 2010). ** Note that the section between Brisbane and New Caledonia (NC) extends between the Australian coast and a point to the south-east of NC; If the end point off NC is taken to be south of NC, the modelled and observed transports are 3.3 and $5.7 \mathrm{~Sv}$, respectively.

Caledonia, and between Sydney and Wellington along frequently repeated XBT lines. The mean transport and the maximum transport along these XBT lines are computed based on geostrophic velocities referenced to $2000 \mathrm{db}$. The modelled and observed mean transports are in good agreement, with estimates within one standard deviation. Similarly, the modelled and observed maximum transports are in agreement, with estimates within one standard deviation. Based on the standard deviation of the EAC transports, it appears that the model has greater variability than the observations, particularly away from the core EAC.

Other well-defined passages include the Florida Current (Hamilton et al., 2004) and the Mozambique Channel (DiMarco et al., 2002). We find that the modelled volume transport of the Florida Current is considerably less than observed. We suspect this is partially because of the decision to "fill in" a large portion of the Great Bahama Bank, as discussed in Appendix A. The volume transport of the modelled Mozambique Channel is within the broad range of observed estimates, and is consistent with other eddy-resolving and eddypermitting models, as described by DiMarco et al. (2002).

\subsection{RMS of SLA, SST, and chlorophyll $a$}

\subsubsection{SLA comparisons}

We compare maps of the RMS of SLA in Fig. 9 for the full model domain, and Figs. 10 and 11 for the key Western Boundary Current (WBC) regions. The SLA comparisons are based on daily mean modelled SLA and weekly maps of SLA on a $1 / 3^{\circ}$ grid, produced by Archiving, Validation, and Interpretation of Satellite Oceanographic data (AVISO; Ducet et al., 2000). The model SLA fields that underpin Figs. 9a and 10 are the model sea level minus the model MSL (shown in Fig. 1a). The observed SLA fields (shown in Figs. 9b and 11) are referenced to the CNES-CLS09 MSL (Fig. 1b) and tend to have larger errors near the coast associated with the correction for tides.

The SLA comparison (Fig. 9) generally shows excellent agreement between the model and observations, with the model reproducing almost all of the local maxima in the observations. The SLA variability is high along the path of the ACC, with good agreement between the model and the observations regarding the location and magnitude of local maxima there. There is also relatively high SLA variability in both the model and the observations in the Indian Ocean, around $25^{\circ} \mathrm{S}$ and $12^{\circ} \mathrm{S}$; off the coast of Somalia; in the western Pacific, off Papua New Guinea and Taiwan; and in the 

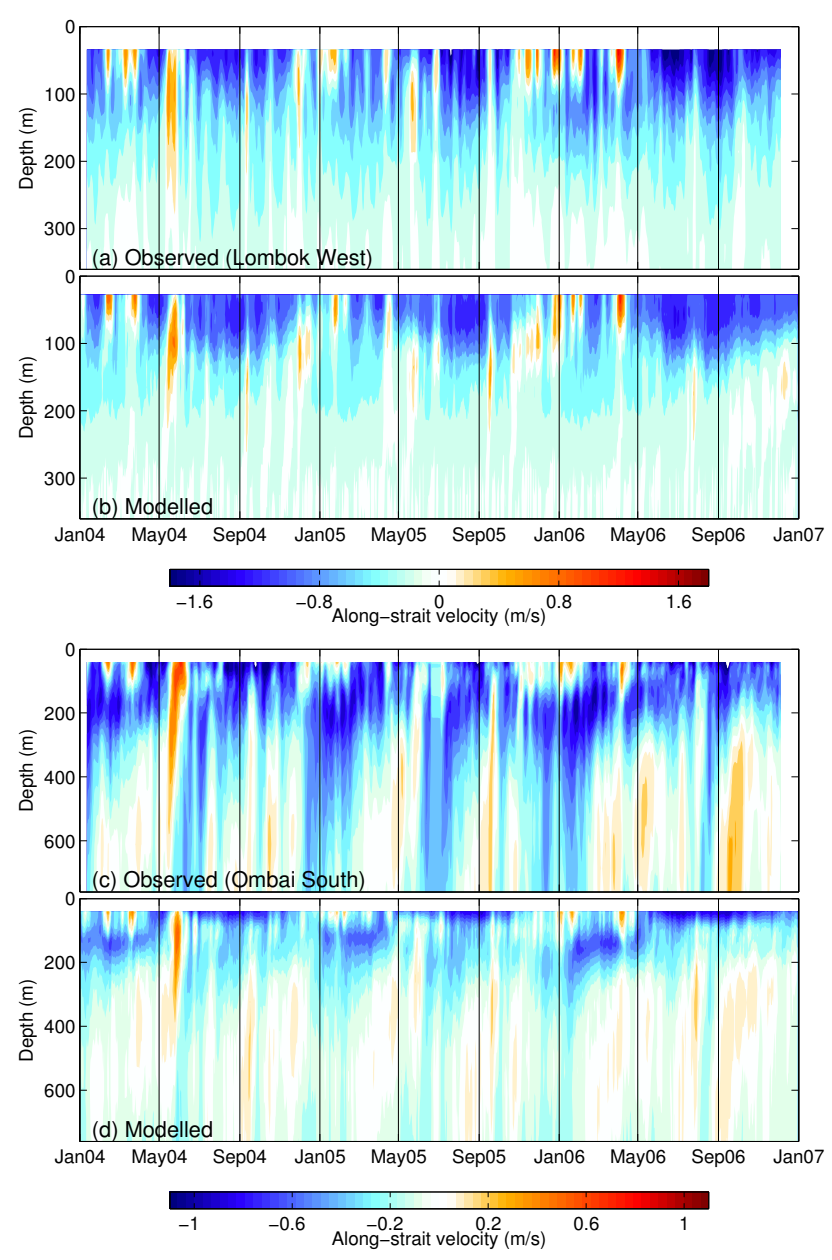

Fig. 8. Time series of (a, c) observed and (b, d) modelled alongstrait velocity at Lombok $\left(\mathbf{a}-\mathbf{b} ; 115^{\circ} 45.55^{\prime} \mathrm{W}, 8^{\circ} 26.34^{\prime} \mathrm{S}\right)$ and Ombai (c-d; $\left.125^{\circ} 0.384^{\prime} \mathrm{E}, 8^{\circ} 38.1^{\prime} \mathrm{S}\right)$ Strait during the INSTANT program (Gordon et al., 2010). Negative (blue) velocities indicate flow towards the Indian Ocean, and positive (red) velocities are towards the Indonesian seas.

central and eastern Pacific at around $5-10^{\circ} \mathrm{N}$. The highest SLA variability is in the WBC regions. These regions are discussed in more detail below.

The comparison in the Kuroshio region shows three distinct local maxima in both the model and the observations (Figs. 10a and 11a), with good agreement between the observed and modelled fields. The modelled SLA variability is greater than observations in the Kuroshio region around $137^{\circ} \mathrm{E}$. This region is where the Kuroshio Current transitions between a meandering phase, with an offshore excursion of the current before re-attaching to the coast, and a non-meandering phase, where the current flows along the coast (e.g. Kawabe, 1995; Qiu and Miao, 2000; Waseda et al., 2003). Observations indicate that transitions occur on timescales of several years (Qiu and Miao, 2000). The higher-than-observed SLA variability in this meander region is an indication that the model transitions between these phases more frequently than in reality. This is supported by analysis of animations of SLA in this region showing the Kuroshio changing phase on irregular timescales - sometimes over several months, and sometimes over a couple of years.

The band of high SLA variability along the path of the Gulf Stream extension is narrower in the observations than in the model (Figs. 9, 10b, and 11b). Also, the band of high variability includes a discontinuity at about $45^{\circ} \mathrm{W}, 42^{\circ} \mathrm{N}$, where the Gulf Stream splits into the North Atlantic Current and the Azores Current (Gould, 1985). This discontinuity is evident in both the model and observations - but has a more pronounced north-eastward turn in the observations compared to the model. Maltrud and McClean (2005) found the same problem with their $1 / 10^{\circ}$-resolution model, reporting that the Gulf Stream extension did not turn northeastward sharply enough around the Grand Banks - but instead continued eastward across the Atlantic.

The comparison of the RMS of SLA in the Agulhas region shows good agreement between the model and the observations (Figs. 9, 10c, and 11c), including a band of high SLA variability along the paths of the Mozambique Current (de Ruijter et al., 2002), the East Madagascar Current, and the Agulhas retroflection. To the north-west of the RMS SLA maxima in the Agulhas region, the model shows a region of high variability, denoting the path of Agulhas rings (e.g. Dencausse and Arhan, 2010) that is weaker in the observations. This error was also reported for other $1 / 10^{\circ}$-resolution (e.g, Maltrud and McClean, 2005; van Sebille et al., 2012; Biastoch et al., 2009) models and is an indication that the path of Agulhas rings in the model is too regular.

The modelled and observed RMS for SLA in the EAC region (Figs. 9, 10d, and 11d) shows good agreement, with a local maximum at about $33^{\circ} \mathrm{S}, 154^{\circ} \mathrm{E}$. The magnitude of the modelled SLA variability at this maximum, off south-eastern Australia, is less than observed. Conversely, the model shows high SLA variability at about $25^{\circ} \mathrm{S}$ and east of $160^{\circ} \mathrm{E}$. This feature appears further east in the observations, but with a smaller magnitude. It is possible that the higher-thanobserved SLA variability in this region acts to dissipate energy from the South Equatorial Current that is "feeding" the EAC. This could partly explain why the variability of SLA south of the EAC separation point is less than observed.

In the BMC region, the SLA has high variability (Figs. 9, 10e, and 11e) over a C-shaped region, around a local minimum at about $45^{\circ} \mathrm{W}, 45^{\circ} \mathrm{S}$; with a local maximum at about $50^{\circ} \mathrm{W}, 42^{\circ} \mathrm{S}$. The BMC region also has a local maximum in SLA variability along a path extending from Drake Passage. The location of the local SLA variability maximum at the confluence of the Brazil and Malvinas Currents is misplaced by about 1-2 degrees in the model, compared to the observations. This displacement is consistent with the systematic differences in the modelled and observed MSL (Fig. 1), indicating that the mean flow and the 


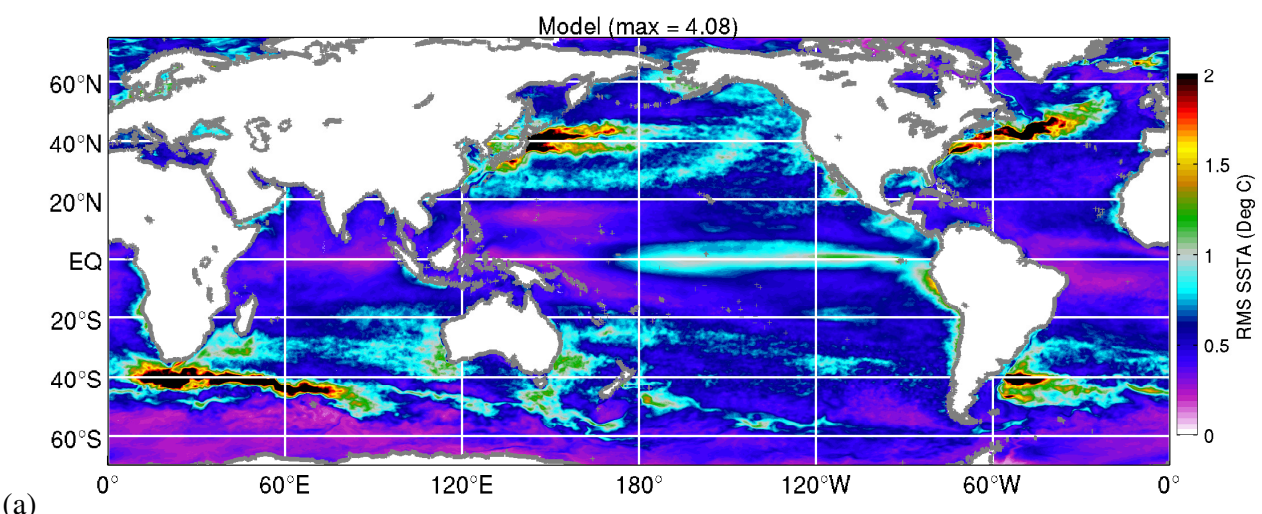

(a)

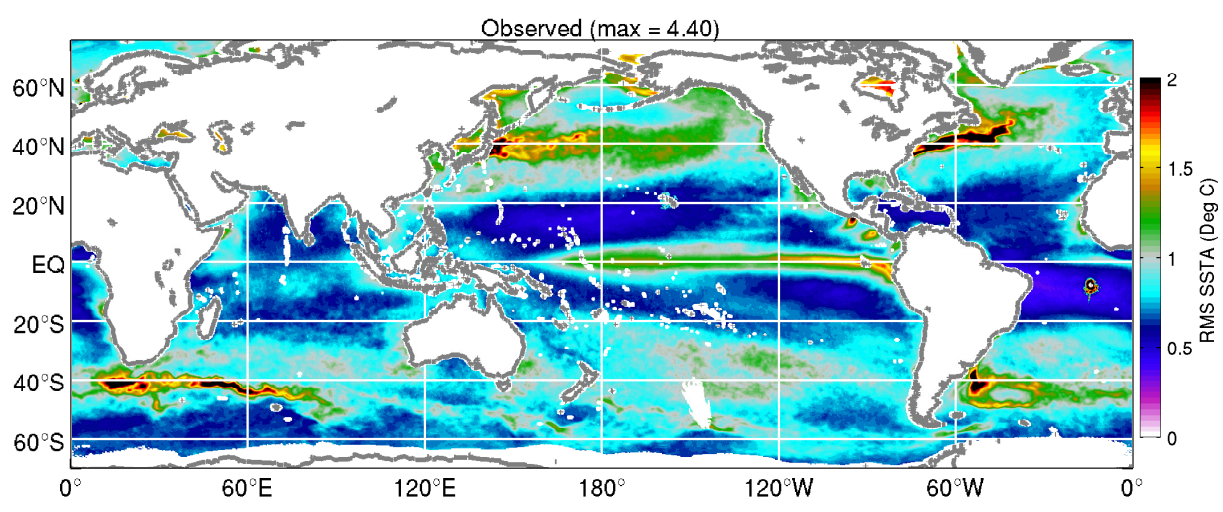

Fig. 9. Comparison of the RMS SLA from the (a) model and (b) observations. The title of each panel includes the global maximum value of RMS SLA that is off the colour scale used.

\section{RMS of Modelled SLA}
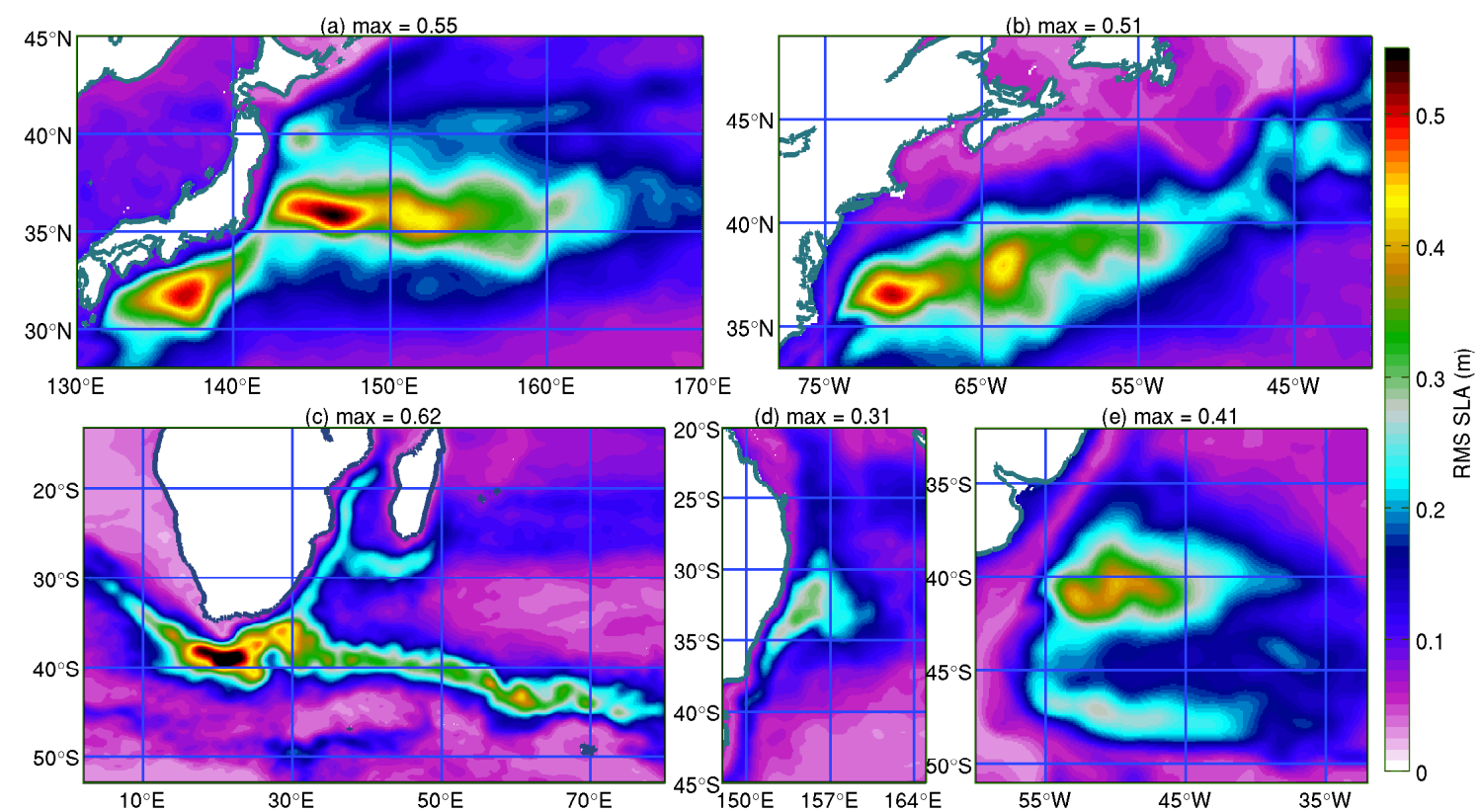

Fig. 10. RMS modelled SLA for the (a) Kuroshio, (b) Gulf Stream, (c) Agulhas, (d) EAC, and the (e) BMC region. The colour scheme is different for different regions according to the inserted legend. 


\section{RMS of Observed SLA}
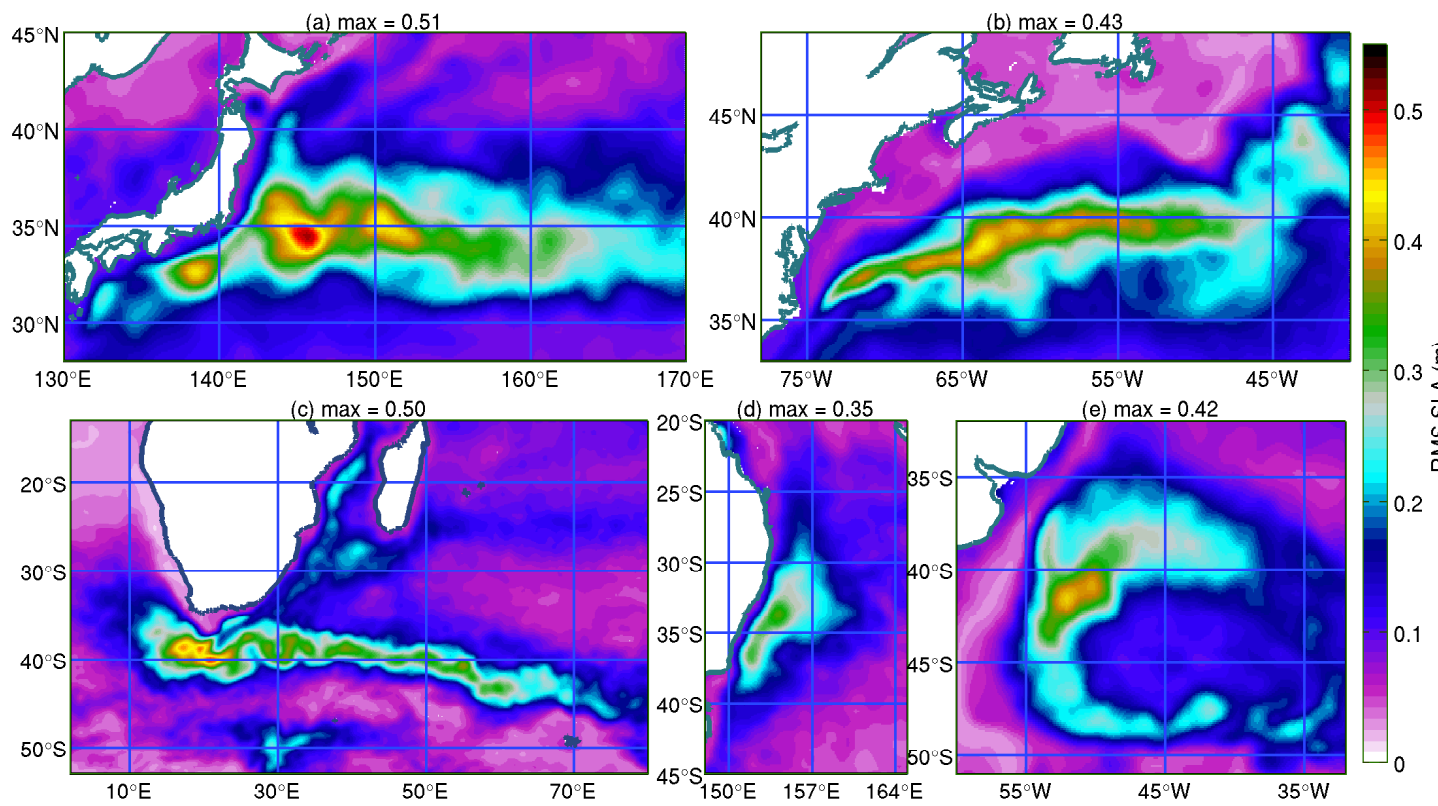

Fig. 11. As for Fig. 10, except for observations.

(a)
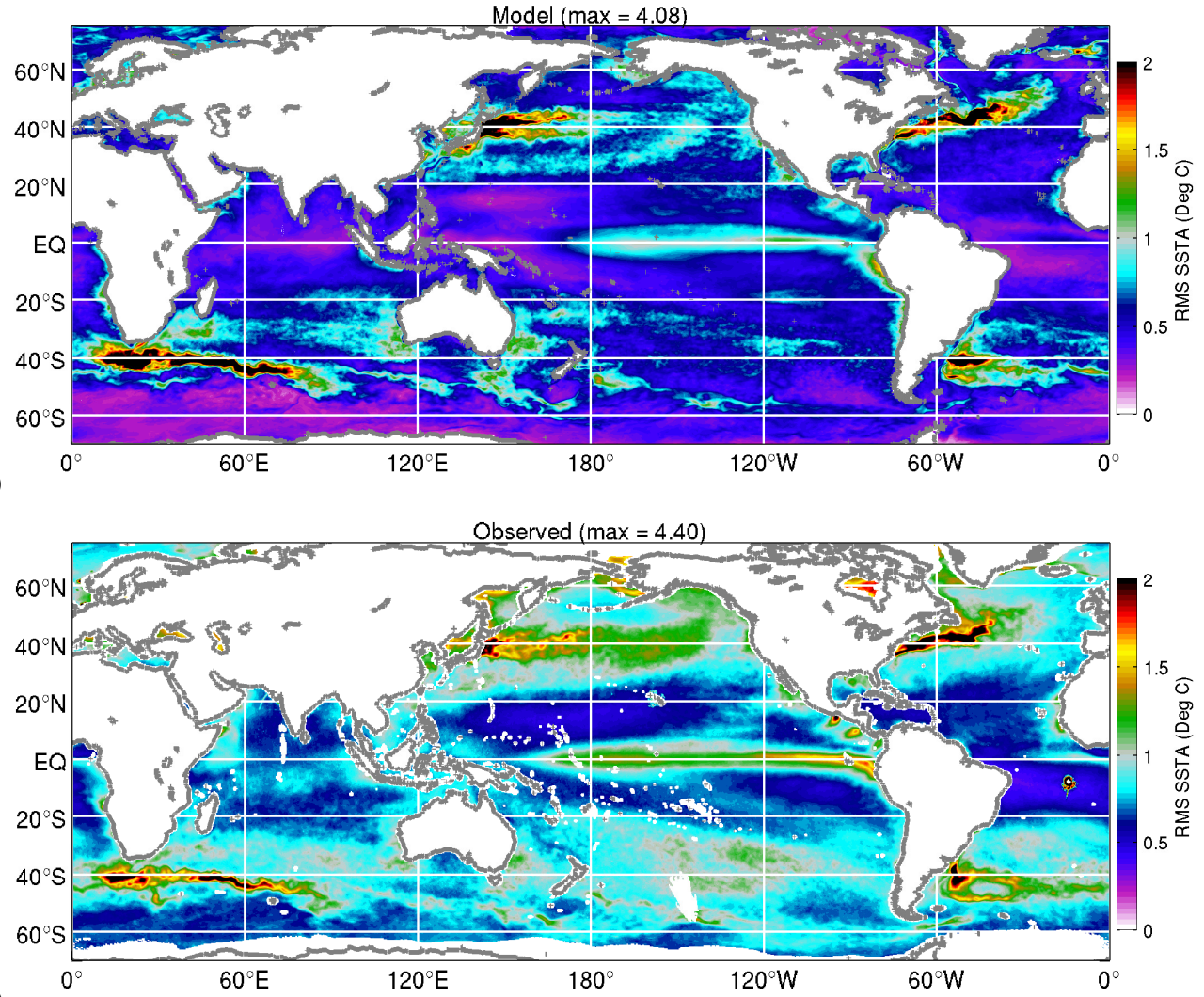

Fig. 12. Comparison of the RMS SSTA from the (a) model and (b) observations. 


\section{RMS of Modelled SSTA}

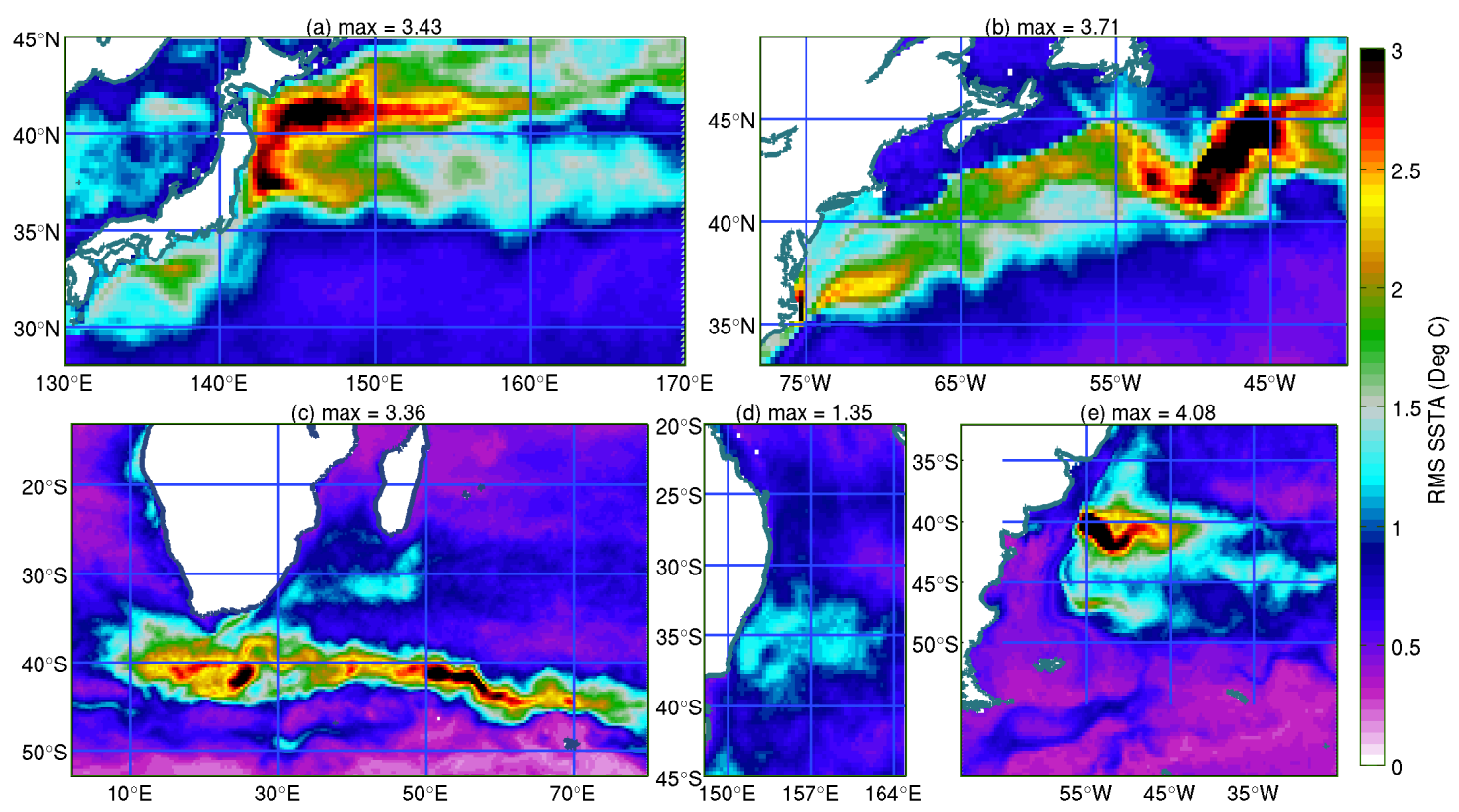

Fig. 13. RMS modelled SSTA for the (a) Kuroshio, (b) Gulf Stream, (c) Agulhas, (d) EAC, and the (e) BMC region. The colour scheme is different for different regions according to the inserted legend.

associated variability is displaced by a degree or two in the model compared to observations.

\subsubsection{SST anomaly comparisons}

We compare maps of the RMS of SST anomaly (SSTA) from the model and from observations in Fig. 12 for the full model domain, and for the key WBC regions in Figs. 13 and 14. The SSTA comparisons are based on 7-day averaged modelled SSTA and 7-day averaged AMSR-E SSTA observations. The SSTA fields in Fig. 12 are anomalies from the seasonal cycle. So, for the RMS of the modelled (observed) SSTA, the seasonal cycle from the model (observations) is first removed from 7-day averaged model (observational) fields and the RMS of the resulting anomaly is computed. The observed AMSR-E SST fields tend to have larger errors near the coast (we have retained only observations that are over water depths $>50 \mathrm{~m}$ ), and have been excluded from the analysis presented in Fig. 12. The SSTA comparisons (Figs. 12, 13 and 14) demonstrate that the model reproduces most of the observed local maxima in the RMS of SSTA. In regions where the SST variability is relatively low (e.g. between $5-25^{\circ} \mathrm{N}$ and between $130^{\circ} \mathrm{E}$ and $140^{\circ} \mathrm{W}$ in the Pacific Ocean), the modelled SSTA is less than the observations by about $0.25-0.5^{\circ} \mathrm{C}$. O'Carroll et al. (2008) suggested that the RMS of the measurement error of AMSR-E SST is about $0.42^{\circ} \mathrm{C}$. This indicates that in the regions where the SSTA variability is small (between $0.5-0.7^{\circ} \mathrm{C}$ ), the signal in the observations is likely to be dominated by measurement error because the signal-to-noise ratio is low. So the lowerthan-observed variability in the model may be an overestimate in the observed RMS, rather than an underestimate in the model. Conversely, where the SSTA variability is high (e.g. in the WBC regions), the modelled SSTA is generally greater than the observed SSTA (Fig. 12).

The SSTA fields in the WBC regions show some interesting differences (Figs. 13 and 14). The differences between the RMS of the modelled and observed SSTA fields are greatest of all the WBC regions in the Kuroshio region (Figs. 13a and 14a). The model SSTA variability includes three regions of local maxima at around $33^{\circ} \mathrm{N}, 37^{\circ} \mathrm{N}$, and $41^{\circ} \mathrm{N}$. The two northernmost bands are also evident in the observations, though with smaller amplitudes, but the southernmost band is less clear in the observations (but the model maximum appears to be over the continental shelf, which is not well depicted in the observational maps).

In the Gulf Stream region (Figs. 13b and 14b) there is high SSTA variability offshore of where the Gulf Stream separates from the coast $\left(\sim 35-36^{\circ} \mathrm{N}\right)$ and at about $50^{\circ} \mathrm{W}$, where the Gulf Stream splits into the North Atlantic Current and the Azores Current (Gould, 1985). Although the model SSTA variability is generally greater than the observations, the locations of the local maxima generally agree well with observations.

In the Agulhas region (Figs. 13c and 14c) there are several local maxima that line up nicely in both the model and the observations. This includes local maxima at about $13^{\circ} \mathrm{E}$ and $20^{\circ} \mathrm{E}$, and a band of high SSTA variability between $45^{\circ} \mathrm{E}$ 


\section{RMS of Observed SSTA}
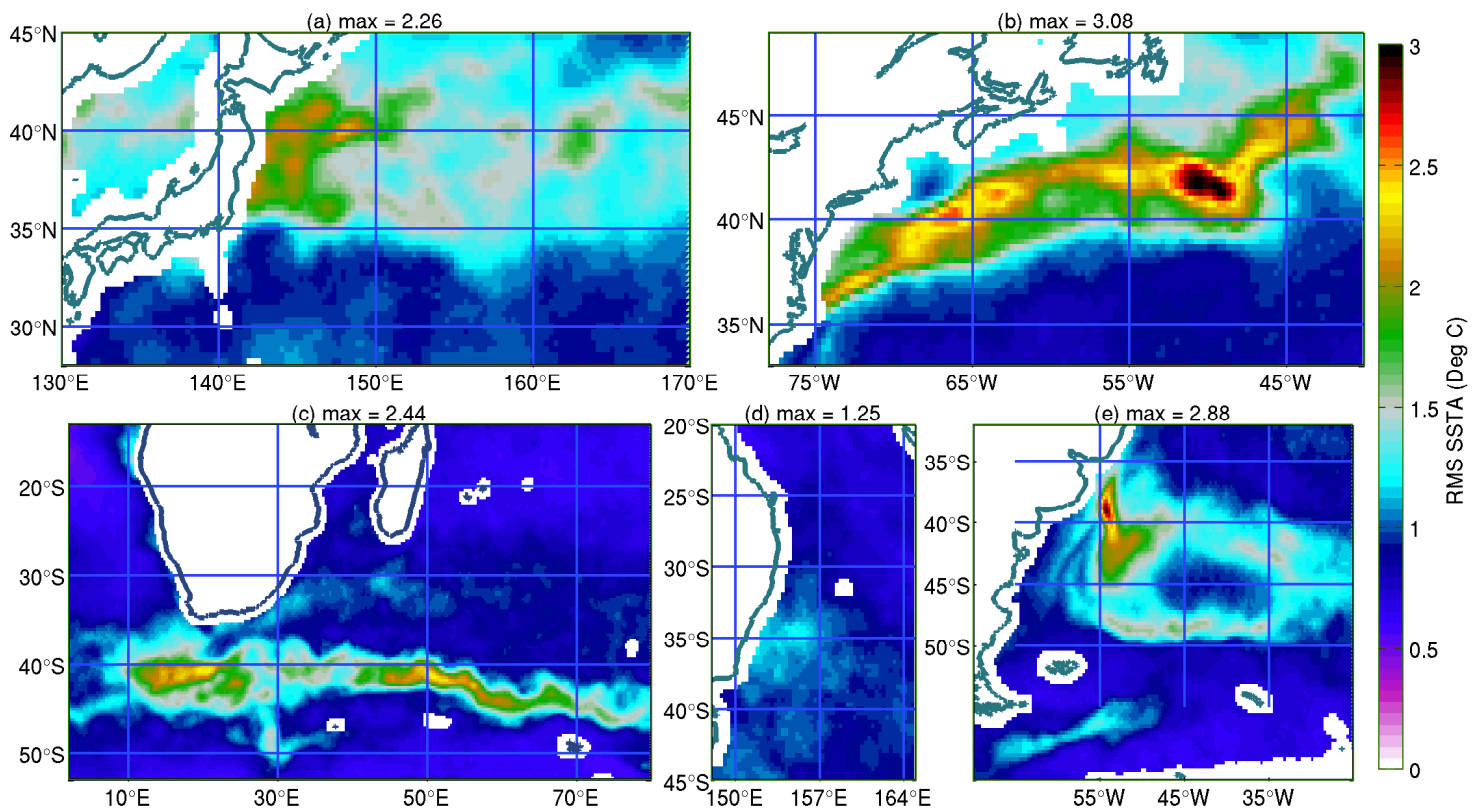

Fig. 14. As for Fig. 13, except for observations.

and $65^{\circ} \mathrm{E}$ along the path of the ACC. There is also a local maximum in both the model and the observations at about $30^{\circ} \mathrm{E}, 50^{\circ} \mathrm{S}$. Again, although the model SSTA variability is generally greater than the observations, the locations of the local maxima agree well with observations.

In the EAC region (Figs. 13d and 14d) the area of high SSTA variability is consistent in both the model and observations - associated with the EAC eddy field. However, the model also shows a band of high SSTA variability extending from the Australian coastline at about $25^{\circ} \mathrm{S}$. This feature is less clear in the observations. A similar maximum is also evident in the model SLA fields, and almost absent in the observed SLA fields. Clearly, the model represents some variability in that region that is weaker in the observations.

In the BMC region (Figs. 13e and 14e), the SSTA fields have a zonal band of high values at about $42^{\circ} \mathrm{S}$ and $48^{\circ} \mathrm{S}$. The observed SSTA variability also shows a narrow band of high variability stemming eastwards from the Drake Passage. This feature is not clearly evident in the model fields.

In general, we find that in the major WBCs, the locations of the local maxima of SSTA in the model are in good agreement with the observations (Figs. 13 and 14). However, we find that the model variability is generally larger than that evident in the observations. We attribute this difference to the use of specified fluxes (with no feedback between the ocean and atmosphere) - rather than a bulk formula for the surface heat flux (which would include a sensible and latent heat component that involves a form of restoring to atmospheric temperature).

\subsubsection{Chlorophyll comparisons}

We compare maps of the root-mean-square (RMS) of surface chlorophyll $a$ from the model and from observations in Fig. 15. The surface chlorophyll $a$ comparisons are between daily mean model estimates (produced by converting surface phytoplankton to chlorophyll $a$ ) and 8-day $9 \mathrm{~km}$ composite maps from SeaWiFS for 1997-2008. The evaluation of chlorophyll $a$ is more complicated than the assessment of SLA and SSTA for several reasons. Firstly, the conversion of modelled phytoplankton concentration (in nitrogen units, mmol m$\left.{ }^{-3}\right)$ to chlorophyll $a$ concentration $\left(\mathrm{mgChl} a \mathrm{~m}^{-3}\right)$ assumes a fixed ratio of $\mathrm{C}: \mathrm{Chl} a$ of $50: 1$ and $\mathrm{C}: \mathrm{N}$ of $106: 16$, and is known to be an approximation (Taylor et al., 1997). Secondly, satellite-derived chlorophyll $a$ is based on estimates of the water leaving radiance that is sensitive to poorly known corrections of the atmosphere on radiances. Thirdly, satellite-derived chlorophyll $a$ tends to be underestimated in the Southern Ocean (Clementson et al., 1998), and overestimated near the coast and sea ice because of the influence of dissolved organic matter and sediment resuspension (Moore et al., 2007). Finally, the nominal uncertainty in the SeaWiFS and MODIS estimates of chlorophyll $a$ in the open ocean water is $\pm 25-35 \%$ (Behrenfeld et al., 2006; Moore et al., 2009). Because of these uncertainties in the observations, we focus our BGC evaluation on assessing the spatial patterns of the modelled and observed chlorophyll $a$ variability.

In a broad sense the modelled and "observed" chlorophyll $a$ variability (Fig. 15) shows similar patterns of high 
(a)
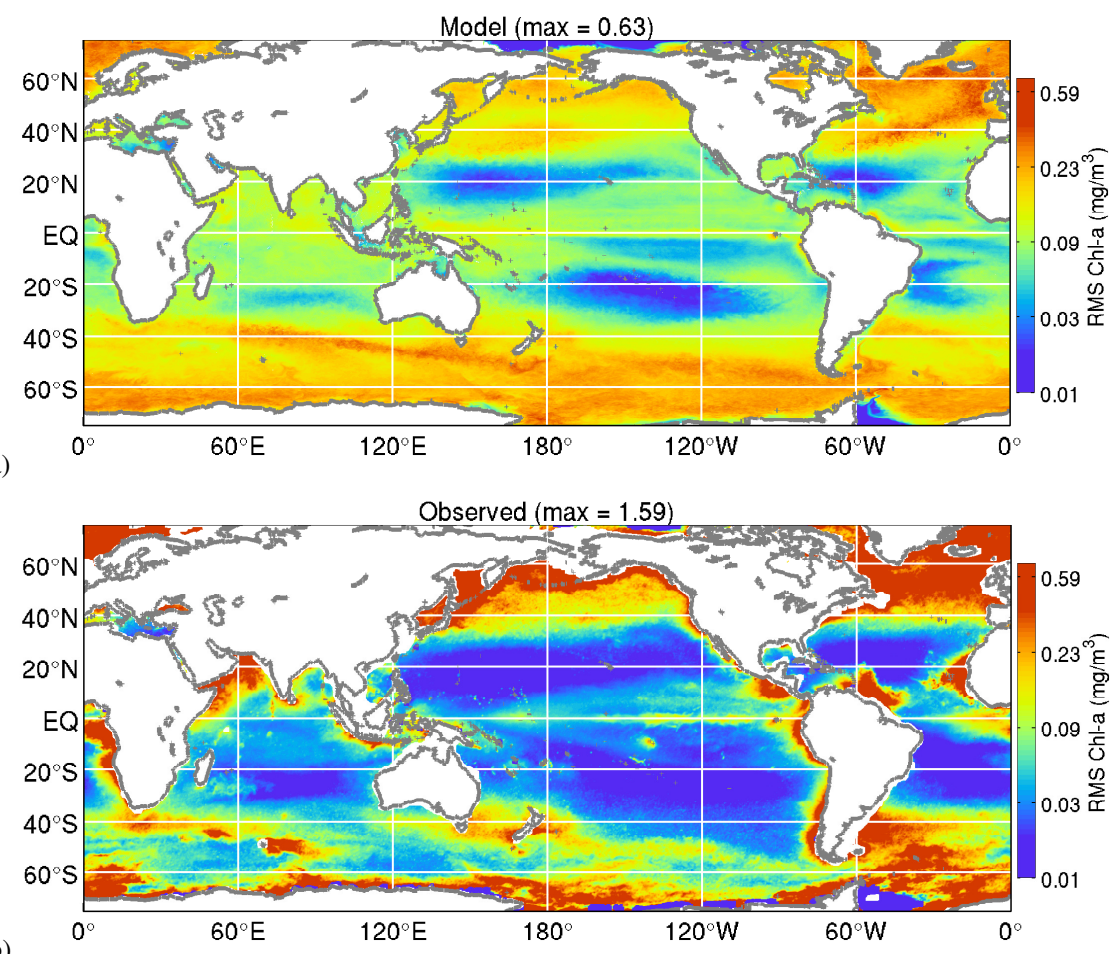

Fig. 15. Comparison of the RMS of the surface chlorophyll $a$ from the model (top) and from SeaWiFS (bottom).

variability at high latitudes, and low variability in the oligotrophic gyres. There are clearly large discrepancies between the modelled and observed surface chlorophyll $a$ fields in many regions. In part, this is because the observed chlorophyll $a$ includes the impacts of mechanisms that are not included in the model, including iron fertilisation from sediments and sea ice melt. The biggest differences in Fig. 15 are adjacent to continental shelves and along the sea ice edge, where the observed variability includes variability associated with processes not represented in the model. Within the interior of each ocean gyre, the model tends to have more variability in chlorophyll $a$ than observed. This may be due to the systematic errors in the model's MLD - with the model generally showing mixed layers that are too deep. This means that the model tends to entrain more sub-surface nutrients into the euphoric layers of the ocean, "stimulating" phytoplankton growth at higher levels than observed. This difference may also be a limitation of a BGC model with a single phytoplankton class - and may be improved if multiple size classes were used (Follows et al., 2007; Baird and Suthers, 2007). By contrast, the model shows weaker variability in regions where wind-driven upwelling is prevalent (e.g. Canary Current, Peru/Chile Current, US west coast, Indonesian coast), probably due to limitations in horizontal and vertical resolution.

\subsubsection{Relating SLA, SST, and chlorophyll $a$ comparisons}

The RMS of modelled and observed SLA, SSTA, and chlorophyll $a$ (Figs. 9, 12, and 15) show regions of high variability in all WBC regions. However, on a broad scale, it appears that the locations of the maxima in the RMS fields are different for each variable. The maxima in the RMS of SSTA and chlorophyll $a$ occur at the latitude of the strongest meridional gradient. The SSTA maxima in the Kuroshio, Gulf Stream, Agulhas, and EAC regions are at higher latitudes than the SLA maxima. This is because there is a large signal in SSTA associated with the intersection of the quasi-isothermal, warm WBC waters with colder higher latitude waters. Because the WBC flow is generally poleward, the SSTA maxima are poleward of the SLA maxima. This characteristic is less clear in the BMC region, probably because the northward flow of the Malvinas Current, east of Argentina, advects the colder ACC waters northward into the path of the warmer Brazil Current, as well as vice versa. As a result, the maxima in SLA and SSTA in the BMC region are more closely co-located. The modelled chlorophyll $a$ maximum in each WBC region is generally equatorward, and sometimes eastward, of the SLA maximum. In each basin, the mean chlorophyll $a$ has a maximum at around $40^{\circ} \mathrm{N}$ and $\mathrm{S}$ (not shown) - and the maximum for the RMS of the modelled chlorophyll $a$ is on the poleward edge of this maximum. We suspect that the maximum in the RMS chlorophyll $a$ field 


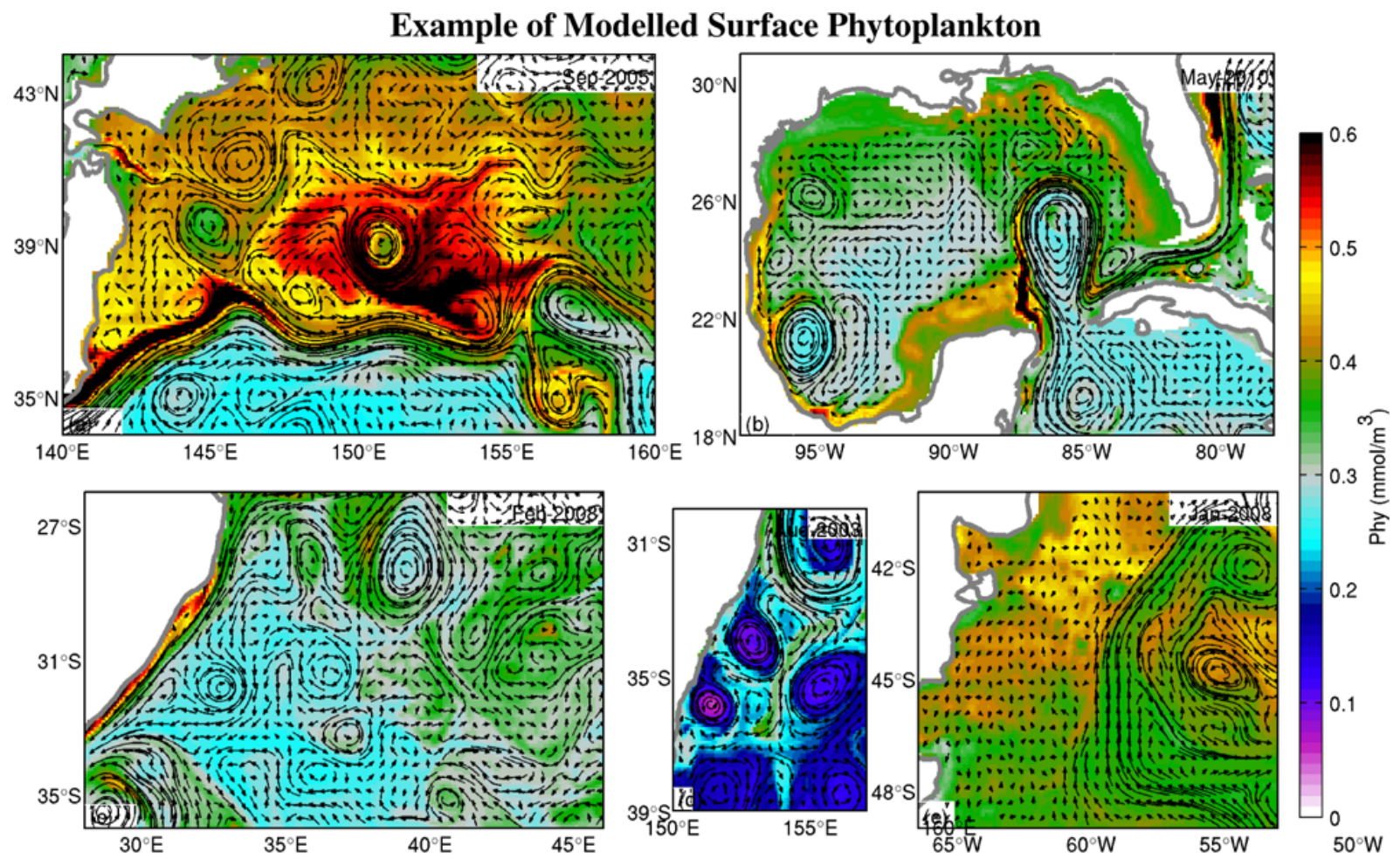

Fig. 16. Example of daily averaged modelled surface phytoplankton for the (a) Kuroshio, (b) Gulf of Mexico, (c) Agulhas, (d) EAC, and (e) BMC region. The daily averaged velocity at $50 \mathrm{~m}$ depth is overlaid on the model fields, with one vector every $0.4^{\circ}$. The length of each vector represents the trajectory of a particle over 2 days.

is due to the confluence of the high chlorophyll $a$ waters around $40^{\circ} \mathrm{N}$ and $\mathrm{S}$, towards the centre of each gyre, with the low-chlorophyll $a$ waters of each WBC.

At mid-southern latitudes, there is high SLA and SSTA variability (Figs. 9 and 12) in both the model and observations in the Leeuwin Current region, and between 20$30^{\circ} \mathrm{S}$ across the Indian Ocean. In the tropics, both the model and observations show high SLA and SSTA variability to the west of the ITF region between about $8-12^{\circ} \mathrm{S}$ that is most likely associated with seasonal Rossby waves (Masumoto and Meyers, 1998) - though the modelled SSTA does not show the high variability that is evident in the observations, as discussed above. Both the model and observations show high SLA and SSTA variability associated with the Great Whirl off Somalia, where a corresponding maximum in chlorophyll $a$ variability is evident in the observations and (to a lesser extent) the model. Broad regions of high SLA variability, associated with instabilities originating in the Kuroshio Current to the east of the Philippines $\left(\sim 10^{\circ} \mathrm{N}\right)$ and east of Taiwan $\left(\sim 22^{\circ} \mathrm{N}\right)$, are evident in both the model and the observations. High SLA variability is evident in the Gulf of Mexico, associated with the Loop Current, in both the model and observations, coincident with a local maximum in SSTA.

There are two zonal bands of high SLA variability (Fig. 9) in the central and eastern tropical Pacific, at about $5^{\circ} \mathrm{N}$ and $10^{\circ} \mathrm{N}$ that are associated with the North Equatorial Current and the North Equatorial Counter Current respectively. The SSTA fields (Fig. 12) show maxima in the Pacific Ocean along the Equator, extending from the coast of South America to about $150-160^{\circ} \mathrm{E}$. In the same region, the chlorophyll $a$ fields show high variability along the Equator. These features are evident in both the model and observations, although the modelled SLA and SSTA variability is weaker than observed, and the modelled chlorophyll $a$ variability is higher than observed.

\subsection{Snapshots of chlorophyll $a$}

We include a qualitative assessment of the BGC in each WBC region by showing a series of "snapshots" of modelled surface phytoplankton (Fig. 16) and satellite-derived chlorophyll $a$ from MODIS (Fig. 17). Due to the chaotic nature of the mesoscale circulation, and the lack of data assimilation in the model, we do not expect to see one-to-one agreement between the model and observations. Rather, we expect to see evidence of similar types of features, on similar spatial scales in these fields.

In all regions shown in Figs. 16 and 17, phytoplankton and chlorophyll $a$ fields show features that are clearly associated with eddies, meanders, and high-nutrient filaments. The model velocity field at $50 \mathrm{~m}$ depth is overlaid on the 


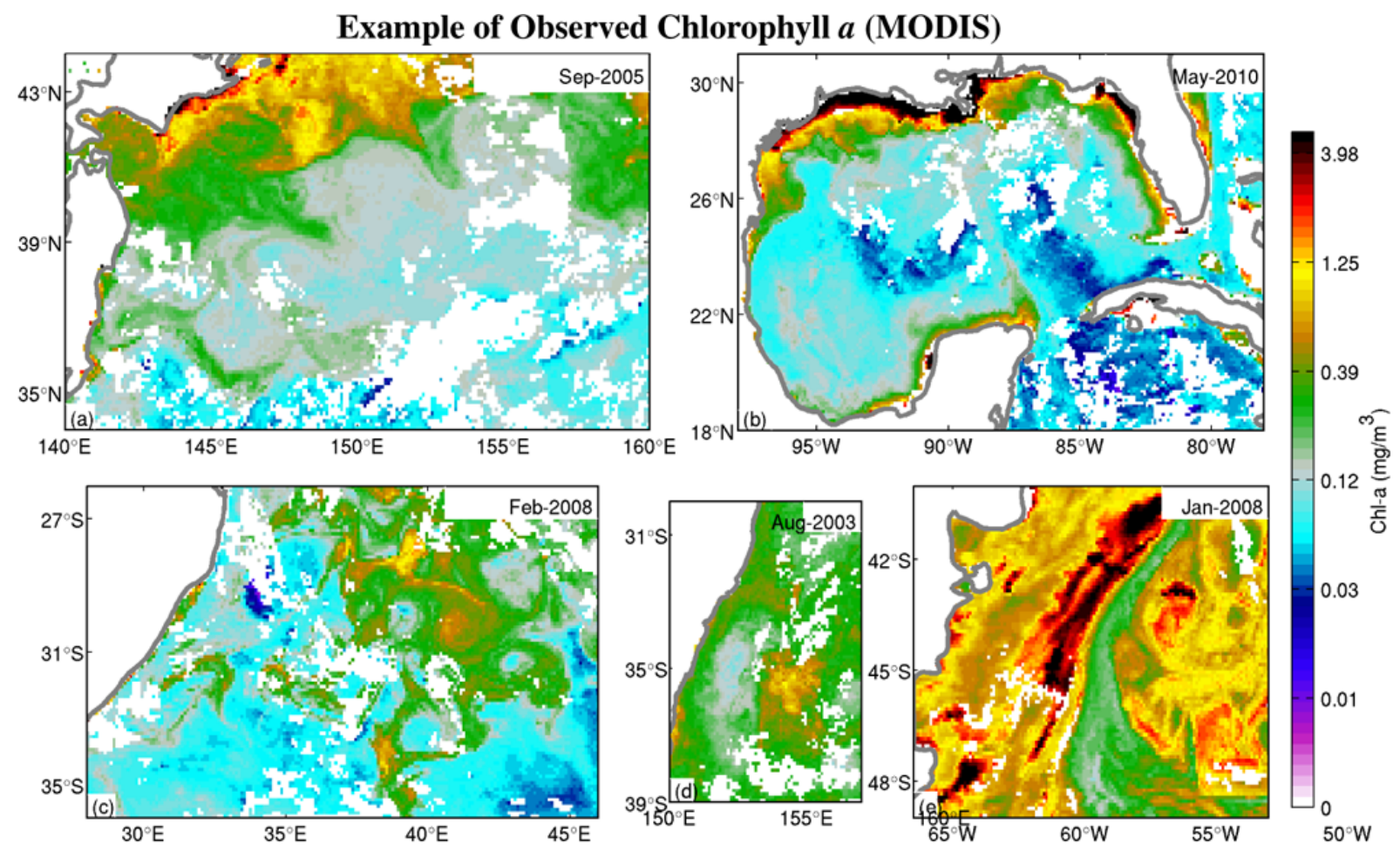

Fig. 17. Example of 8-day composite chlorophyll a from MODIS for the (a) Kuroshio, (b) Gulf of Mexico, (c) Agulhas, (d) EAC, and (e) $\mathrm{BMC}$ region.

model fields to show the nature of the circulation. Strong biophysical coupling is evident in all regions: the Kuroshio region, with mesoscale signals evident in both the model and observations; the Gulf of Mexico, with high BGC activity around the periphery of the Loop Current; in the Agulhas region, with evidence of small-scale mesoscale variability - on scales of a few degrees, in both the modelled phytoplankton and the observed chlorophyll $a$; in the confluence of Malvinas and Brazil currents, with strong features associated with the intersection of different water masses; and in the EAC region, with the signature of mesoscale eddies and meanders evident in both the model and observations.

Interestingly, the model fields (Fig. 17) typically show relatively low phytoplankton in the centre of eddies, with higher phytoplankton around the periphery. The only anti-cyclonic eddies evident in Fig. 16 with elevated phytoplankton in the eddies core are in the $\mathrm{BMC}\left(\sim 55^{\circ} \mathrm{W}, 45^{\circ} \mathrm{S}\right)$ and Agulhas $\left(\sim 36^{\circ} \mathrm{E}, 28^{\circ} \mathrm{S} ; 41^{\circ} \mathrm{E}, 35^{\circ} \mathrm{S}\right)$. For most other anti-cyclonic eddies, there is elevated phytoplankton flowing around the eddy. Good examples of this include the eddies in the centre of the Kuroshio region $\left(\sim 151^{\circ} \mathrm{E}, 39^{\circ} \mathrm{S}\right)$, the the south-west corner of the Gulf of Mexico $\left(\sim 96^{\circ} \mathrm{W}, 21^{\circ} \mathrm{N}\right)$, the Agulhas region $\left(\sim 39^{\circ} \mathrm{E}, 28^{\circ} \mathrm{S}\right)$, and $\mathrm{EAC}\left(\sim 151-157^{\circ} \mathrm{E}\right)$. The anti-cyclonic eddies shown in Fig. 16 are larger than the cyclonic eddies. Elevated phytoplankton in the core of cyclonic eddies are evident in the BMC region $\left(\sim 53^{\circ} \mathrm{W}, 44^{\circ} \mathrm{S}\right)$ and in the EAC region $\left(\sim 158^{\circ} \mathrm{E}, 32^{\circ} \mathrm{S}\right)$. However, consistent with the anti-cyclonic eddies in the model, phytoplankton generally appear higher around the edges of cyclonic eddies (Fig. 16). A more detailed analysis of the biophysical coupling is needed to further explore these relationships. Such studies have previously been undertaken using satellite observations (e.g. Chelton et al., 2011). In a recent study by Everett et al. (2012), it was shown that in one particular zone of the EAC region - that they referred to as "Eddy Avenue" - cyclonic eddies typically have elevated chlorophyll $a$ at their core, while anti-cyclonic eddies have lower than average chlorophyll $a$. These, and other, biophysical relationships relating to the mesoscale ocean circulation could be further examined using data from OFAM3.

\section{Conclusions}

We present initial results from an analysis of the variability in the last $18 \mathrm{yr}$ of a $32 \mathrm{yr}$ run of OFAM3 - a new near-global eddy-resolving ocean general circulation model. Comparisons between the RMS of SLA from the model and from gridded observations indicate that the model variability is realistic, with local maxima and minima in the same locations as observations and with similar magnitude. Similarly, comparisons between the RMS of SSTA from the model and from gridded observations show local maxima and minima in the same locations as observations, except the model tends to overestimate the magnitude of SST anomalies in 
regions of high variability, such as WBC regions. Analyses of the model's MSL, MLD, volume transports through key straits and passages, zonally averaged temperature, salinity and MOC lead us to conclude that the model average state is realistic; and that the model realistically represents the variability in the upper ocean and at intermediate depths. Nevertheless, a few systematic errors are evident in the model. For example, the modelled mixed layer is generally too deep in mid-latitudes, and in some regions (e.g. the Brazil-Malvinas Confluence) the modelled variability is along a different path to that observed from altimetry. The impact of these errors is evident on the modelled BGC fields that are evaluated here by comparisons with satellite observations. We find that the variability of the modelled chlorophyll $a$ is generally too high - a characteristic that we attribute (in part) to the model's systematic errors in MLD. Despite these systematic errors, we have shown that the modelled variability is generally realistic; and we conclude that the model variability is suitable for further analysis to better understand ocean dynamics, variability, teleconnections and so on.

The next step for OFAM3 is the performance of a $20 \mathrm{yr}$ ocean reanalysis (with data assimilation), similar to that described by Oke et al. $(2005,2008)$ and Schiller et al. (2008). Subsequent to that activity, OFAM3 is intended to be used in the next generation of the operational ocean forecast system at the Australian Bureau of Meteorology. The next phase of technical developments of the OFAM model will likely include the development of a truly global model, including the Arctic Ocean with coupling to a sea ice model. Other planned developments include the adoption of bulk surface heat fluxes, instead of prescribed fluxes, and the application of an atmospheric boundary layer model. We expect that these developments will help address some of the shortcomings identified in this study.

\section{Appendix A}

\section{OFAM3}

\section{A1 Resolution}

OFAM3 is a near-global (i.e. non-Arctic) eddy-resolving configuration of version 4p1 of the Modular Ocean Model (Griffies, 2009, December 2009 release), developed principally for the purpose of hindcasting and forecasting upper ocean conditions in non-polar regions. The model grid has $1 / 10^{\circ}$ grid spacing for all longitudes and between $75^{\circ} \mathrm{S}$ and $75^{\circ} \mathrm{N}(\sim 8-11 \mathrm{~km} \times 11 \mathrm{~km})$ and is comprised of $3600 \times 1500$ grid points. The vertical model coordinate is $z^{*}$ (Griffies, 2009), with 51 vertical levels, with resolution grading from $5 \mathrm{~m}$ at the surface to $10 \mathrm{~m}$ between 100 and $200 \mathrm{~m}$ depth, then $120 \mathrm{~m}$ at $1000 \mathrm{~m}$, and eventually $1000 \mathrm{~m}$ near the sea floor. Also, we use partial grid cells (Adcroft et al., 1997) to improve the representation of topography and to improve the vertical resolution near the bottom. We set the minimum height for each partial cell to be no less than $5 \mathrm{~m}$ or $20 \%$ of the full cell height, whichever is greater $\left(\Delta z_{\text {partial }}>\max \left(5 \mathrm{~m}, 0.2 \times \Delta z_{\text {full }}\right)\right)$.

\section{A2 Topography}

The topography for OFAM3 is derived from the 30 arcsecond GEBCO_08 topography (www.bodc.ac.uk/data/ online_delivery/gebco/) for most of the world, and a 9 arcsecond topography produced by Geoscience Australia (Whiteway, 2009). The minimum number of vertical levels in the model is 3 , so the minimum depth in the model is $15 \mathrm{~m}$. In regions where the real topography is less than $15 \mathrm{~m}$, the model topography is set to either zero (i.e. land) or to $15 \mathrm{~m}$. Often the decision to "fill in" or "dig out" a grid cell is subjective. In some cases (e.g. Torres Strait, Indonesian straits) some points are filled in, and others dug out so that the correct cross-sectional area of a strait is preserved. In other areas where a broad region is shallow, large areas are sometimes filled in with land (e.g. Great Bahama Bank), and sometimes set to the minimum depth (e.g. southern Persian Gulf). Additionally, some inland or regional seas are replaced with land either because they are out of the scope for planned applications of this model (e.g. Caspian Sea, Sea of Azov), to avoid problems with computational stability, or to avoid problems with the northern boundary (e.g. Laptev Sea, Kara Sea).

\section{A3 Forcing}

OFAM3 is forced with $1.5^{\circ}$-resolution, 3-hourly surface heat, freshwater, and momentum fluxes from ERA-Interim (Dee and Uppala, 2009). The surface heat flux is applied to the top model layer for components associated with the latent, sensible and long-wave heat flux. The penetrating short-wave heat flux is applied over multiple model levels according to a single exponential decay law, with penetration depths based on SeaWiFS Kd-490 (e.g. Lee et al., 2005). The SeaWiFS Kd490 is a measure of the turbidity of the water column that quantifies the depth over which short-wave radiation penetrates the ocean. The model forcing includes climatological, seasonal river forcing estimated by Dai and Trenberth (2002) and Dai et al. (2009). River forcing is applied as a water flux, with the injection of zero-salinity water and local SST distributed over the top 3 model layers at coastal grid points. Surface temperature and salinity are relaxed to monthly averaged Reynolds SST (Reynolds et al., 2007) and monthly averaged CARS salinity (CSIRO Atlas of Regional Seas, released in 2009; Ridgway and Dunn, 2003) with a nominal restoring timescale of 10 days and 30 days, respectively. The impact of variability in the Arctic Ocean is included by restoring the temperature and salinity over all depths within 1 degree of the northern boundary to monthly averaged fields from version 2.1.6 of the Simple Ocean Data Assimilation 
(SODA; Carton et al., 2000; Carton and Giese, 2008, accessed on October 2010) between 1993 and 2008, using a restoring timescale of 30 days. After 2008, we restore to a seasonal climatology based on SODA. Meridional velocities at the northern and southern boundaries are zero, with a noslip condition for zonal velocities. To avoid any significant drift in the deep ocean fields, the temperature and salinity are restored to CARS climatology below $2000 \mathrm{~m}$ with a restoring timescale of 365 days.

\section{A4 Initialisation and integration}

The model was initialised at rest, with zero sea level, and with potential temperature and salinity from a global version of CARS (Ridgway and Dunn, 2003). The model was spun up for $14 \mathrm{yr}$, spanning the period 1993-2005, with timevarying forcing, as described above. The temperature, salinity, sea level, and velocity fields at the end of 2005 were used as initial conditions for a second run spanning the period 1993-2010. The analyses presented in this paper are based on model years 14-32, spanning the period 1993-2010, and excludes the initial $14 \mathrm{yr}$ spin-up period.

\section{A5 Numerics}

The time step is $540 \mathrm{~s}$ for model tracers, and $6 \mathrm{~s}$ for sea level and depth-integrated velocities. A staggered forward time step is used for tracers and velocity (Griffies, 2004, Sect. 12.6). The model time step is typically limited by vertical velocities at about $200 \mathrm{~m}$ depth. A third-order AdamsBashforth scheme is used for velocity advection, and a thirdorder upwind biased scheme is used for tracers (Hundsdorfer and Trompert, 1994), in conjunction with a flux limiter scheme (Sweby, 1984). A predictor-corrector time-filter is also applied to sea level using a non-dimensional damping parameter of $\gamma=0.2$, as recommended by Griffies (2004, Sect. 12.7).

\section{A6 Mixing parameterisations}

OFAM3 uses the mixed layer model described by Chen et al. (1994). The background vertical diffusivity and viscosity are $1 \times 10^{-5}$ and $1 \times 10^{-4} \mathrm{~m}^{2} \mathrm{~s}^{-1}$, respectively. The maximum vertical diffusivity and viscosity due to shear instabilities are $5 \times 10^{-3} \mathrm{~m}^{2} \mathrm{~s}^{-1}$ and $2.5 \times 10^{-3}$, respectively (though we note that recent sensitivity experiments suggest that that maximum viscosity may be too low - resulting in stronger-thanexpected vertical shears in the velocity over the top 2 or 3 layers). Additional vertical mixing is applied over the water column to represent the mixing effects of tides following Lee et al. (2006) (using a Munk-Anderson-P and MunkAnderson-Sigma parameter of 0.25 and 3.0, respectively). This results in stronger mixing in regions of large-amplitude tides, such as the north-west of Australia. The tidal mixing coefficients depend on spatially resolved, but time invariant

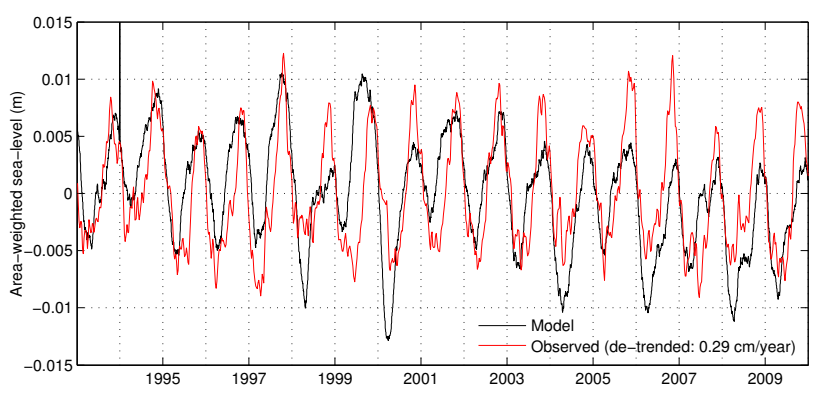

Fig. A1. Time series of area-weighted global mean sea level from the model (black) and observations (red), each relative to their own time means. The linear trend has been removed from the observations that are based on gridded sea level anomaly maps from AVISO.

estimates of tidal amplitudes that are obtained from a global inverse model (Egbert et al., 1994).

A convective adjustment is applied every time step using fully explicit mixing when the water column becomes unstable. The explicit horizontal diffusion is zero. Horizontal viscosity is resolution- and state-dependent using a biharmonic Smagorinsky viscosity scheme (Griffies and Hallberg, 2000), with an isotropic parameter of 3.0 and an anisotropic parameter of 3.0.

\section{A7 Volume conservation}

OFAM3 is configured to be volume-conserving $\left(z^{*}\right)$. Thermal expansion is therefore not included in the model. As a result, the thermostatic component of observed sea level rise that is evident in observations (e.g. Church and White, 2006) is not reproduced in OFAM3. However, the globally averaged sea level of the simulated ocean is sensitive to any imbalance between the prescribed precipitation, evaporation, and river forcing. The globally averaged net freshwater flux from ERA-Interim (Dee and Uppala, 2009) is not zero. We find that the annually and globally averaged evaporation always exceeds precipitation (and river forcing), so we apply a very small spatially uniform precipitation - a "drizzle" that is fixed for each year of the spin-up run so that the net volume flux is zero. A similar approach was used by Balmaseda et al. (2008) for a coarse-resolution global ocean reanalysis and seasonal prediction system. The mean annual "drizzle" that is applied accounts for a sea level change of $0.06 \mathrm{~m} \mathrm{yr}^{-1}$. For comparison, the mean annual sea level change due to the other components of the freshwater budget is $-1.31 \mathrm{~m} \mathrm{yr}^{-1}$ for evaporation; $0.43 \mathrm{~m} \mathrm{yr}^{-1}$ for large-scale precipitation; $0.72 \mathrm{~m} \mathrm{yr}^{-1}$ for convective precipitation; and $0.1 \mathrm{~m} \mathrm{yr}^{-1}$ for river run-off. The model is not intended for studies of sea level rise, so it does not include forcing from glacial melt.

Time series of the area-weighted global mean sea level from the model and from observations are shown in Fig. A1. 
By design, the model does not have a trend in the global mean sea level, but the time mean of $-1.8 \mathrm{~cm}$ has been removed from the model. The time mean of $1.6 \mathrm{~cm}$ and the linear trend of $0.29 \mathrm{~cm} \mathrm{yr}^{-1}$ have been removed from the observations. The seasonal fluctuations of the globally averaged sea level have a magnitude of between 1 and $2 \mathrm{~cm}$, in agreement with the observations, in both phase and amplitude. Because a greater area of the Southern (Northern) Hemisphere is covered by ocean (land), the global mean sea level has a minimum in late austral summer - owing to evaporation over the Southern Hemisphere and snow accumulation over the Northern Hemisphere.

\section{Appendix B}

\section{WOMBAT}

Details of the ocean biogeochemical (BGC) processes included in the Whole Ocean Model of Biogeochemistry And Trophic-dynamics (WOMBAT) model are described below. This model is based on a NPZD (nutrient-phytoplanktonzooplankton-detritus) model with the addition of bioavailable iron limitation $(\mathrm{Fe})$, dissolved inorganic carbon (DIC), calcium carbonate $\left(\mathrm{CaCO}_{3}\right)$, alkalinity (ALK), and oxygen $(\mathrm{O})$. In this model we have one class each of phytoplankton and zooplankton. These are calculated on the same grid as temperature.

The following equations parameterise the biogeochemical transformations between the various BGC state variables of WOMBAT with the BGC model parameters summarised in Table B1. In addition to the these BGC transformations, the BGC state variables are transported around the ocean using the same physical equations as used for $T$ and $S$. For Fe, DIC and oxygen in the surface layer, there are also air-sea flux terms which are discussed below.

$$
\begin{aligned}
\frac{\mathrm{dP}}{\mathrm{d} t} & =\bar{J}(z, t, T, \mathrm{~N}, \mathrm{Fe}) \mathrm{P}-G(\mathrm{P}, \mathrm{Z})-\mu_{\mathrm{P}} \mathrm{P} \\
\frac{\mathrm{d} Z}{\mathrm{~d} t} & =\gamma_{1} G(\mathrm{P}, \mathrm{Z})-\gamma_{2} \mathrm{Z}-\mu_{\mathrm{Z}} \mathrm{Z}^{2} \\
\frac{\mathrm{dD}}{\mathrm{d} t} & =\left(1-\gamma_{1}\right) G(\mathrm{P}, \mathrm{Z})+\mu_{\mathrm{Z}} \mathrm{Z}^{2}-\mu_{\mathrm{D}} \mathrm{D}-w_{\mathrm{D}} \frac{\mathrm{dD}}{\mathrm{d} z} \\
\frac{\mathrm{dN}}{\mathrm{d} t} & =\mu_{\mathrm{D}} \mathrm{D}+\gamma_{2} \mathrm{Z}+\mu_{\mathrm{P}} \mathrm{P}-\bar{J}(z, t, T, \mathrm{~N}, \mathrm{Fe}) \mathrm{P} \\
\frac{\mathrm{dFe}}{\mathrm{d} t} & =0.02 \frac{\mathrm{d} \mathrm{N}}{\mathrm{d} t}-\tau_{\text {scav }} \max (0, \mathrm{Fe}-0.6)
\end{aligned}
$$

Equation (B1) describes phytoplankton growth $(\bar{J}(z, t, T, \mathrm{~N}, \mathrm{Fe}) \mathrm{P})$, loss due to zooplankton grazing $(G(\mathrm{P}, \mathrm{Z}))$, and phytoplankton mortality $\left(\mu_{\mathrm{P}} \mathrm{P}\right)$. Phytoplankton growth rate is a function of temperature $(T)$, light $(I)$ and nutrient concentrations ( $\mathrm{N}$ and $\mathrm{Fe}$ ) and the growth rate is given by

$$
\begin{aligned}
\bar{J}(z, t, T, \mathrm{~N}, \mathrm{Fe}) & =J_{\max }(T) \\
& \times \min \left[\frac{J(z, t, T)}{J_{\max }(T)}, \frac{\mathrm{N}}{\mathrm{N}+k_{\mathrm{N}}}, \frac{\mathrm{Fe}}{\mathrm{Fe}+k_{\mathrm{Fe}}}\right] \\
J(z, t, T) & =J_{\max }(T)\left(1-\exp \left(\frac{-\alpha I(z, t)}{J_{\max }(T)}\right)\right) \\
I(z, t) & =\operatorname{PAR} \times I(0, t) \times \operatorname{Frac}(z) \\
J_{\max }(T) & =a b^{c T},
\end{aligned}
$$

where $J_{\max }$ is the maximum phytoplankton growth at a given $T$, assuming no light or nutrient limitation; $J(z, t, T)$ is the impact of light on growth rate, and is based on Westwood et al. (2011), PAR is the photosynthetically available radiation, $I(0, t)$ is the time-varying incident solar radiation at the surface, and $\operatorname{Frac}(z)$ is the light attenuation that is obtained from a single exponential decay law, with penetration depths based on SeaWiFS Kd-490 (which was the same as the value used by the Chen et al. (1994) mixing scheme).

Equation (B2) describes the zooplankton, represented as the balance between growth due to phytoplankton grazing $(G(\mathrm{P}, \mathrm{Z}))$ and losses due to zooplankton excretions $\left(\gamma_{2} \mathrm{Z}\right)$ and mortality $\left(\mu_{Z} Z^{2}\right)$. The grazing of phytoplankton by zooplankton $(G(\mathrm{P}, \mathrm{Z}))$ is given by

$G(\mathrm{P}, \mathrm{Z})=\frac{g \epsilon \mathrm{P}^{2}}{g+\epsilon \mathrm{P}^{2}} \mathrm{Z}$,

where $\gamma_{1}$ is the efficiency of zooplankton grazing on phytoplankton, while the remainder becomes detritus.

Equation (B3) describes the detritus field, and includes input from zooplankton grazing and mortality, as well as terms for detrital decomposition $\left(\mu_{\mathrm{D}} \mathrm{D}\right)$ and sinking $\left(w_{\mathrm{D}} \frac{\mathrm{dD}}{\mathrm{d} z}\right)$. The detrital decomposition is a function of temperature to reflect the enhance bacterial activity in warmer water (e.g. Rivnin, 2001) and is allowed to occur when oxygen is zero through the process of denitrification. The process of denitrification decomposes detritus liberating the nutrients (i.e. phosphate and iron) without consuming oxygen, and in this way the oxygen concentrations can never be less than zero. The sinking term transports detritus vertically downward through the water column. In the deep ocean detritus remineralises back into inorganic form, completing the nutrient cycle.

Equation (B4) describes the nutrient (phosphate) field that is controlled by physical supply (upwelling and vertical mixing) and phytoplankton growth rate and remineralisation. We assume a Redfield ratio of $1: 16: 106:-172\left(\mathrm{P}: \mathrm{N}: \mathrm{C}: \mathrm{O}_{2}\right)$ with phosphate, nitrate, carbon and oxygen. The choice of phosphate as our macro-nutrient rather than nitrate allows us to neglect nitrification, denitrification and atmosphere deposition, which add and remove nitrate from the ocean and make the nitrogen cycle more complicated than the phosphate cycle, which is conserved in the ocean.

An additional source of limitation on phytoplankton growth rate is iron $(\mathrm{Fe})$, which is described by Eq. (B5). 
Table B1. Model parameters of the BGC model were set to the values optimised in the 1-D model of the North Atlantic (Schartau and Oschlies, 2003).

\begin{tabular}{|c|c|c|c|}
\hline Parameter & Symbol & Value & Units \\
\hline \multicolumn{4}{|l|}{ Phytoplankton model parameters } \\
\hline Initial slope of $\mathrm{P}-I$ curve & $\alpha$ & 0.025 & day $^{-1} /\left(\mathrm{W} \mathrm{m}^{-2}\right)$ \\
\hline Photosynthetically active radiation & PAR & 0.43 & - \\
\hline \multirow[t]{3}{*}{ Maximum growth rate parameters } & $a$ & 0.6 & day $^{-1}$ \\
\hline & $b$ & 1.066 & - \\
\hline & $c$ & 1.0 & $\mathrm{C}^{-1}$ \\
\hline Half saturation constant for $\mathrm{N}$ uptake & $k_{\mathrm{N}}$ & 1.0 & $\mathrm{mmol} \mathrm{N} \mathrm{m}^{-3}$ \\
\hline Half saturation constant for Fe uptake & $k_{\mathrm{Fe}}$ & 1.0 & $\mathrm{mmol} \mathrm{N} \mathrm{m}^{-3}$ \\
\hline Phytoplankton mortality & $\mu_{\mathrm{P}}$ & $0.01 b^{c T}$ & day $^{-1}$ \\
\hline \multicolumn{4}{|l|}{ Zooplankton model parameters } \\
\hline Assimilation efficiency & $\gamma_{1}$ & 0.85 & - \\
\hline Maximum grazing rate & $g$ & 2.1 & day $^{-1}$ \\
\hline Prey capture rate & $\epsilon$ & 1.1 & $\left(\mathrm{mmol} \mathrm{N} \mathrm{m}{ }^{-2}\right)^{-1}$ day $^{-1}$ \\
\hline Quadratic mortality & $\mu_{\mathrm{Z}}$ & 0.06 & $\left(\mathrm{mmol} \mathrm{N} \mathrm{m}{ }^{-3}\right)^{-1}$ day $^{-1}$ \\
\hline Excretion & $\gamma_{2}$ & $0.01 b^{c T}$ & day $^{-1}$ \\
\hline \multicolumn{4}{|l|}{ Detritus model parameters } \\
\hline Remineralisation rate $(<180 \mathrm{~m})$ & $\mu_{\mathrm{D}}$ & $0.02 b^{c T}$ & day $^{-1}$ \\
\hline Remineralisation rate $(\geq 180 \mathrm{~m})$ & $\mu_{\mathrm{D}}$ & $0.01 b^{c T}$ & day $^{-1}$ \\
\hline Sinking velocity & $w_{\mathrm{D}}$ & 5.0 & $\mathrm{mday}^{-1}$ \\
\hline \multicolumn{4}{|l|}{$\mathrm{CaCO}_{3}$ model parameters } \\
\hline Remineralisation rate & $\mu_{\mathrm{CaCO} 3}$ & 0.0035 & day $^{-1}$ \\
\hline Sinking velocity & $w_{\mathrm{D}}$ & 10.0 & $\mathrm{~m}_{\mathrm{day}}{ }^{-1}$ \\
\hline \multicolumn{4}{|l|}{ Fe model parameters } \\
\hline Scavenging rate & $\tau_{\mathrm{Fe}}$ & 1.0 & day $^{-1}$ \\
\hline
\end{tabular}

Iron is supplied to the ocean by dust deposition at the surface (Mongin et al., 2011) and from sediments where the depth is less than $200 \mathrm{~m}$ (Mongin et al., 2009). Changes in iron are related to phosphate uptake, using a molar ratio for Fe : $\mathrm{P}$ of $2.0 \times 10^{-5}: 1 / 16$ (Christian et al., 2002), and iron is scavenged when it has a concentration $>0.6 \mu \mathrm{mol} \mathrm{m}{ }^{-3}$, which works to maintain the deep ocean iron concentration at this value (Archer and Johnson, 2000). Calcium carbonate $\left(\mathrm{CaCO}_{3}\right)$ production is fixed at $8 \%$ of detritus production (Yamanaka and Tajika, 1996), and is given by

$$
\begin{aligned}
& \frac{\mathrm{d} \mathrm{CaCO}_{3}}{\mathrm{~d} t}=\frac{0.08 \times 106}{16}\left(\left(1-\gamma_{1}\right) G(\mathrm{P}, \mathrm{Z})+\mu_{\mathrm{Z}} \mathrm{Z}^{2}\right) \\
& -\mu_{\mathrm{caco} 3} \mathrm{CaCO}_{3}-w_{\mathrm{caco} 3} \frac{\mathrm{d} \mathrm{CaCO}_{3}}{\mathrm{~d} z} \\
& \frac{\mathrm{d} \mathrm{O}_{2}}{\mathrm{~d} t}=-\frac{172}{16} \frac{\mathrm{dN}}{\mathrm{d} t} \\
& \frac{\mathrm{d} \mathrm{DIC}}{\mathrm{d} t}=\frac{106}{16} \frac{\mathrm{dN}}{\mathrm{d} t}-\frac{\mathrm{d} \mathrm{CaCO}_{3}}{\mathrm{~d} t} \\
& \frac{\mathrm{d} \mathrm{ALK}}{\mathrm{d} t}=-\frac{\mathrm{d} \mathrm{N}}{\mathrm{d} t}-2 \frac{\mathrm{d} \mathrm{CaCO}_{3}}{\mathrm{~d} t} \text {. }
\end{aligned}
$$

In the model we include two DIC tracers, represented here by Eq. (B13), for the natural and anthropogenic DIC. These two DIC tracers only differ in the atmospheric $\mathrm{CO}_{2}$ concentration used in the air-sea flux calculation. For the natural DIC the atmospheric $\mathrm{CO}_{2}$ was set to $280 \mathrm{ppm}$ while for anthropogenic DIC the atmospheric $\mathrm{CO}_{2}$ increases according to observations. At the surface we calculated the airsea exchange of the two carbon tracers and oxygen following Lenton and Matear (2007), which uses the partial difference pressures between the ocean and atmosphere, the seasonal climatology of sea ice concentrations, and the wind speed squared and temperature-dependent gas exchange coefficient. The initial conditions for $\mathrm{P}$ and $\mathrm{O}_{2}$ are derived by the 2005 version of the World Ocean Atlas (WOA2005; Garcia et al., 2006a,b). Chlorophyll was taken from a climatology of SeaWiFS (1997-2008) and then scaled to P to initialise phytoplankton in the top $100 \mathrm{~m}$, using the ratio P : Chl $a=1 / 16 \mathrm{mmol} \mathrm{m}^{-3} \mathrm{P}: 1.59 \mathrm{mg} \mathrm{m}^{-3} \mathrm{Chl} a$ ). Zooplankton $(Z)$ were initially estimated to be 0.05 of the initial phytoplankton concentration. The initial field for Fe was taken from a $500 \mathrm{yr}$ integration of a coarser resolution simulation with the same BGC module. Preindustrial DIC was 
initialised from GLODAP (Key et al., 2004). To generate the annual mean fields of DIC and ALK for the nominal year 1997, we started with the observed climatology of Takahashi et al. (2009) from the year 2000, and then calculated ALK and DIC following Lenton et al. (2012) using the annual mean sea surface and salinity from WOA2005 from Locarnini et al. (2006) and Antonov et al. (2006) respectively. To correct the DIC to 1997, we used the observed global atmospheric growth rate from Mauna Loa (Earth System Research Laboratory, 2009) and the approximation of the Revelle factor (Sarmiento and Gruber, 2006). We then calculated the difference in the surface between our calculated DIC and ALK, and GLODAP DIC and ALK (Key et al., 2004), and corrected the entire water column based on this surface difference.

To assess the variability of the modelled phytoplankton, we convert it to chlorophyll $a$ (using a $1 / 16: 1.59$ ratio as described above), and compare it to chlorophyll $a$ estimates from SeaWiFS. We show the RMS of the model-derived chlorophyll $a$ and satellite-derived chlorophyll $a$ from SeaWiFS in Fig. 15, and a series of "snapshots" of modelled phytoplankton and satellite-derived chlorophyll $a$ from MODIS in Fig. 17. These comparisons involve several assumptions and several limitations. The satellite measurements include the impacts of mechanisms that are not included in the model, including iron fertilisation from sediments and sea ice melt. Also, the conversion of modelled phytoplankton concentration to chlorophyll $a$ concentration involves several assumptions, as described in Sect. 3.7.3.

Acknowledgements. Funding for this research was provided by CSIRO, through the Wealth from Oceans National Research Flagship, and through the Royal Australian Navy. The authors gratefully acknowledge contributions from the Bluelink science team; and comments from P. Sakov, S. Cravatte, and W. Kessler that led to improvements in this manuscript. Satellite altimetry is provided by NASA, NOAA and CNES. SST observations are provided by NOAA (www.nodc.noaa.gov) and Remote Sensing Systems (www.remss.com).

Edited by: R. Redler

\section{References}

Adcroft, A., Hill, C., and Marshall, L.: Representation of topography by shaved cells in a height coordinate ocean model, Mon. Weather Rev., 125, 2293-2315, 1997.

Antonov, J. I., Locarnini, R. A., Boyer, T. P., Mishonov, A. V., and Garcia, H. E.: World Ocean Atlas 2005, Volume 2: Salinity, in: NOAA Atlas NESDIS, edited by: Levitus, S., 182 pp., US Government Printing Office, Washington, DC, 2006.

Archer, D. E. and Johnson, K.: A Model of the iron cycle in the ocean, Global Biogeochem. Cy., 14, 269-279, 2000.

Baird, M. E. and Suthers, I. M.: A size-resolved pelagic ecosystem model, Ecol. Model., 203, 185-203, doi:10.1016/j.ecolmodel.2006.11.025, 2007.
Balmaseda, M. A., Vidard, A., and Anderson, D. L. T.: The ECMWF ocean analysis system: ORA-S3, Mon. Weather Rev., 136, 3018-3034, doi:10.1175/2008MWR2433.1, 2008.

Behrenfeld, M. J., O’Malley, R. T., Siegel, D. A., McClain, C. R., Sarmiento, J. L., Feldman, G. C., Milligan, A. J., Falkowski, P. G., and Letelier, R. M.: Climate-driven trends in contemporary ocean productivity, Nature, 444, 752-755, 2006.

Biastoch, A., Böning, C. W., Scheinert, M., and Lutjeharms, J. R. E.: The Agulhas System as a Key Region of the Global Oceanic Circulation, in: High Performance Computing in Science and Engineering '08, edited by: Nagel, W. E., Kröner, D. B., and Resch, M. M., Springer Berlin Heidelberg, 459-469, 2009.

Brassington, G. B., Pugh, T. F., Spillman, C., Schulz, E., Beggs, H., Schiller, A., and Oke, P. R.: BLUElink development of operational oceanography and servicing in Australia, J. Research Pract. Inf. Tech., 39, 151-164, 2007.

Carton, J. A. and Giese, B. S.: A reanalysis of ocean climate using Simple Ocean Data Assimilation (SODA), Mon. Weather Rev., 136, 2999-3017, 2008.

Carton, J. A., Chepurin, G., and Cao, X.: A Simple Ocean Data Assimilation analysis of the global upper ocean 1950-95, Part II: Results, J. Phys. Oceanogr., 30, 311-326, 2000.

Chelton, D. B., Gaube, P., Schlax, M. G., Early, J. J., and Samelson, R. M.: The influence of nonlinear mesoscale eddies on near-surface oceanic chlorophyll, Science, 334, 328-332, doi:10.1126/science.1208897, 2011.

Chen, D., Rothstein, L., and Busalacchi, A.: A hybrid vertical mixing scheme and its application to tropical ocean models, J. Phys. Oceanogr., 24, 2156-2179, 1994.

Christian, J. R., Verschell, M. A., Murtugudde, R., Busalacchi, A. J., and McClain, C. R.: Biogeochemical modelling of the tropical Pacific Ocean I. Seasonal and interannual variability, Deep-Sea Res., 49, 545-565, 2002.

Church, J. A. and White, N. J.: A 20th century acceleration in global sea-level rise, Geophys. Res. Lett., 33, L01602, doi:10.1029/2005GL024826, 2006.

Clementson, L. A., Parslow, J. S., Griffiths, F. B., Lyne, V. D., Mackey, D. J., Harris, G. P., McKenzie, D. C., Bonham, P. I., Rathbone, C. A., and Rintoul, S.: Controls on phytoplankton production in the Australasian sector of the subtropical convergence, Deep Sea Res., 45, 1627-1661, doi:10.1016/S09670637(98)00035-1, 1998.

Cunningham, S. A., Alderson, S. G., King, B. A., and Brandon, M. A.: Transport and Variability of the Antarctic Circumpolar Current in Drake Passage, J. Geophys. Res., 108, 8084, doi:10.1029/2001JC001147, 2003.

Cunningham, S. A., Kanzow, T., Rayner, D., Baringer, M. O., Johns, W. E., Marotzke, J., Longworth, H. R., Grant, E. M., Hirschi, J. J.-M., Beal, L. M., Meinen, C. S., and Bryden, H. L.: Temporal variability of the Atlantic Meridional Overturning Circulation at 26.5ํํㅇ, Science, 317, 935-938, 2007.

Dai, A. and Trenberth, K. E.: Estimates of freshwater discharge from continents: Latitudinal and seasonal variations, J. Hydrometeor., 3, 660-687, 2002.

Dai, A., Qian, T., Trenberth, K. E., and Milliman, J. D.: Changes in continental freshwater discharge from 1948-2004, J. Climate, 22, 2773-2791, 2009.

de Boyer Montegut, C., Madec, G., Fischer, A. S., Lazar, A., and Iudicone, D.: Mixed layer depth over the global ocean: an examina- 
tion of profile data and a profile-based climatology, J. Geophys. Res., 109, C12003, doi:10.1029/2004JC002378, 2004.

Dee, D. P. and Uppala, S.: Variational bias correction of satellite radiance data in the ERA-Interim reanalysis, Q. J. Roy. Meteorol. Soc., 135, 1830-1841, doi:10.1002/qj.493, 2009.

Dencausse, G. and Arhan, M.: Routes of Agulhas rings in the southeastern Cape Basin, Deep-Sea Res., 57, 1406-1421, doi:10.1016/j.dsr.2010.07.008, 2010.

de Ruijter, W. P. M., Ridderinkhof, H., Lutjeharms, J. R. E., Schouten, M. W., and Veth, C.: Observations of the flow in the Mozambique Channel, Geophys. Res. Lett., 29, 140.1-140.3, 2002.

Dietze, H., Matear, R., and Moore, T.: Nutrient supply to anticyclonic meso-scale eddies off Western Australia estimated with artificial tracers released in a circulation model, Deep Sea Res., 56, 1440-1448, 2009.

DiMarco, S. F., Chapman, P., Nowlin, W. D., Hacker, P., Donohue, K., Luther, M., Johnson, G. C., and Toole, J.: Volume transport and property distributions of the Mozambique Channel, Deep Sea Res., 49, 1481-1511, 2002.

Doos, K., Nycander, J., and Coward, A. C.: Lagrangian decomposition of the Deacon Cell, J. Geophys. Res., 113, C07028, doi:10.1029/2007JC004351, 2008.

Ducet, N., Traon, P.-Y. L., and Reverdin, G.: Global high-resolution mapping of ocean circulation from TOPEX/POSEIDON and ERS-1 and-2, J. Geophys. Res., 105, 19477-19498, 2000.

Earth System Research Laboratory: Cooperative Atmospheric Data 951, in: Integration Project: Carbon Dioxide, [CD-ROM], NOAA, Boulder, 952 Colorado, USA, 2009.

Egbert, G. D., Bennett, A., and FOREMAN, M.: TOPEX/POSEIDON tides estimated using a global inverse model, J. Geophys. Res., 99, 24821-24852, 1994.

Everett, J. D., Baird, M. E., Oke, P. R., and Suthers, I. M.: An avenue of eddies: Quantifying the biophysical properties of mesoscale eddies in the Tasman Sea, Geophys. Res. Lett., 39, L16608, doi:10.1029/2012GL053091, 2012.

Follows, M. J., Dutkiewicz, S., Grant, S., and Chisholm, S. W.: Emergent biogeography of microbial communities in a model ocean, Science, 315, 1843-1846, doi:10.1126/science.1138544, 2007.

Garcia, H. E., Locarnini, R. A., Boyer, T. P., and Antonov, J. I.: World Ocean Atlas 2005, Volume 3: Dissolved Oxygen, Apparent Oxygen Utilization, and Oxygen Saturation, in: NOAA Atlas NESDIS 63, edited by: Levitus, S., 342 pp., US Government Printing Office, Washington, DC, 2006a.

Garcia, H. E., Locarnini, R. A., Boyer, T. P., and Antonov, J. I.: World Ocean Atlas 2005, Volume 4: Nutrients (phosphate, nitrate, silicate), in: NOAA Atlas NESDIS 64, edited by: Levitus, S., 396 pp., US Government Printing Office, Washington, DC, $2006 \mathrm{~b}$

Gordon, A. L., Sprintall, J., Van Aken, H. M., Susanto, D., Wijffels, S. E., Molcard, R., Ffield, A., Pranowo, W., and Wirasantosa, S.: The Indonesian throughflow during 2004-2006 as observed by the INSTANT program, Dynam. Atmos. Oceans, 50, 115-128, doi:10.1016/j.dynatmoce.2009.12.002, 2010.

Gould, W. J.: Physical Oceanography of the Azores Front, Progress Oceanogr., 14, 167-190, 1985.

Griffies, S. M.: Fundamentals of Ocean Climate Models, University Press, Princeton, USA, 2004.
Griffies, S. M.: Elements of MOM4p1, GFDL Ocean Group Technical Report 6, Tech. rep., NOAA/Geophysical Fluid Dynamics Laboratory, 2009.

Griffies, S. M. and Hallberg, R. W.: Biharmonic friction with a Smagorinsky-like viscosity for use in large-scale eddypermitting ocean models, Mon. Weather Rev., 128, 2935-2946, 2000.

Hamilton, P., Larsen, J. C., Leaman, K. D., Lee, T. N., and Waddell, E.: Transports through the Straits of Florida, J. Phys. Oceanogr., 35, 308-322, 2004.

Hundsdorfer, W. and Trompert, R. A.: Method of lines and direct discretization: a comparison for linear advection, Appl. Num. Math., 13, 469-490, 1994.

Kawabe, M.: Variations of current path, velocity, and volume transport of the Kuroshio in relation with the large meander, J. Phys. Ocean., 25, 3103-3117, 1995.

Key, R., Kozyr, A., Sabine, C. L., Lee, K., Wanninkhof, R., Bullister, J. L., Feely, R. A., Millero, F. J., Mordy, C., and Peng, T. H.: A global ocean carbon climatology: Results from Global Data Analysis Project (GLODAP), Global Biogeochem. Cy., 18, GB4031, doi:10.1029/2004GB002247, 2004.

Kidston, M., Matear, R. J., and Baird, M. E.: Parameter optimisation of a marine ecosystem model at two contrasting stations in the Sub-Antarctic Zone, Deep Sea Res., 58, 2301-2315, 2011.

Kohl, A. and Stammer, D.: Interannual to decadal changes in the ECCO Global Synthesis, J. Phys. Oceanogr., 37, 313-337, 2007.

Langlais, C., Schiller, A., and Oke, P. R.: Southern Ocean Fronts in the Bluelink Reanalysis, Mercator Quarterly Newsletter, 36, 50-57, 2010.

Lee, A.-P., Darecki, M., Carder, K. L., Davis, C. O., Stramski, D., and Rhea, W. J.: Diffuse attenuation of coefficient of downwelling irradiance: An evaluation of remote sensing methods, J. Geophys. Res., 110, doi:10.1029/2004JC002573, 2005.

Lee, H.-C., Rosati, A., and Spelman, M.: Barotropic tidal mixing effects in a coupled climate model: ocean conditions in the northern Atlantic, Ocean Model., 11, 464-470, 2006.

Lee, T., Awaji, T., Balmaseda, M., Ferry, N., Fujii, Y., Fukumori, I., Giese, B., Heimbach, P., Kohl, A., Masina, S., Remy, E., Rosati, A., Schodlok, M., Stammer, D., and Weaver, A.: Consistency and fidelity of Indonesian-throughflow total volume transport estimated by 14 ocean data assimilation products, Dynam. Atmos. Oceans, 50, 201-223, doi:10.1016/j.dynatmoce.2009.12.004, 2010.

Lenton, A. and Matear, R. J.: Role of the Southern Annular Mode (SAM) in Southern Ocean CO2 uptake, Global Biogeochem. Cy., 21, GB2016, doi:10.1029/2006GB002714, 2007.

Lenton, A., Metzl, N., Takahashi, T., Kuchinke, M., Matear, R. J., Roy, T., Sutherland, S. C., Sweeney, C., and Tilbrook, B.: The observed evolution of oceanic $\mathrm{pCO} 2$ and its drivers over the last two decades, 26, GB2021, doi:10.1029/2011GB004095, 2012.

Locarnini, R. A., Mishonov, A. V., Antonov, J. I., Boyer, T. P., and Garcia, H. E.: World Ocean Atlas 2005, Volume 1: Temperature, in: NOAA Atlas NESDIS 61, edited by: Levitus, S., 182 pp., US Government Printing Office, Washington, DC, 2006.

Maltrud, M. E. and McClean, J. L.: An eddy resolving global $1 / 10^{\circ}$ ocean simulation, Ocean Model., 8, 31-54, 2005.

Masumoto, Y. and Meyers, G.: Forced Rossby waves in the southern tropical Indian Ocean, J. Geophys. Res., 103, 27589-27602, 1998. 
Matear, R. J.: Parameter optimization and analysis of ecosystem models using simulated annealing: A case study at Station P, J. Mar. Res., 53, 571-607, 1995.

Matear, R. J. and Hirst, A. C.: Long term changes in dissolved oxygen concentrations in the ocean caused by protracted global warming, Global Biogeochem. Cy., 17, 1125-1144, 2003.

Matear, R. J. and Lenton, A.: Impact of Historical Climate Change on the Southern Ocean Carbon Cycle, J. Climate, 21, 5820-5834, 2008.

Mongin, M. M., Matear, R. J., and Chamberlain, M.: Simulation of chlorophyll and iron supplies in the Sub-Antarctic Zone South of Australia, Deep Sea Res., 58, 2126-2134, 2011.

Mongin, M. M., Abraham, E. R., and Trull, T. W.: Winter advection of iron can explain the summer phytoplankton bloom that extends $1000 \mathrm{~km}$ downstream of the Kerguelen Plateau in the Southern Ocean, J. Mar. Res., 67, 225-237, 2009.

Moore, T. M., Matear, R. J., Marra, J., and Clementson, L.: Phytoplankton variability off the Western Australian Coast: Mesoscale eddies and their role in cross-shelf exchange, Deep Sea Res., 54, 943-960, 2007.

Moore, T. S., Campbell, J. W., and Dowell, M. D.: A class-based approach to characterizing and mapping the uncertainty of the MODIS ocean chlorophyll product, Remote Sens. Environ., 113, 2424-2430, doi:10.1016/j.rse.2009.07.016, 2009.

O'Carroll, A. G., Eyre, J. R., and Saunders, R. W.: Three-Way Error Analysis between AATSR, AMSR-E, and In Situ Sea Surface Temperature Observations, J. Atmos. Ocean. Technol., 25, 11971207, 2008.

Oke, P. R. and Griffin, D. A.: The cold-core eddy and strong upwelling off the coast of New South Wales in early 2007, Deep Sea Res., 58, 574-591, doi:10.1016/j.dsr2.2010.06.006, 2011.

Oke, P. R. and Schiller, A.: Impact of Argo, SST, and altimeter data on an eddy-resolving ocean reanalysis, Geophys. Res. Lett., 34, L19601, doi:10.1029/2007GL031549, 2007.

Oke, P. R., Schiller, A., Griffin, D. A., and Brassington, G. B.: Ensemble data assimilation for an eddy-resolving ocean model of the Australian region, Q. J. Roy. Meteorol. Soc., 131, 3301-3311, doi:10.1256/qj.05.95, 2005.

Oke, P. R., Brassington, G. B., Griffin, D. A., and Schiller, A.: The Bluelink Ocean Data Assimilation System (BODAS), Ocean Model., 21, 46-70, doi:10.1016/j.ocemod.2007.11.002, 2008.

Oke, P. R., Sakov, P., Cahill, M. L., Dunn, J. R., Fiedler, R., Griffin, D. A., Mansbridge, J. V., Ridgway, K. R., and Schiller, A.: Towards a dynamically balanced eddy-resolving ocean reanalysis: BRAN3, Ocean Model., doi:10.1016/j.ocemod.2013.03.008, in press, 2013.

Qiu, B. and Miao, W.: Kuroshio Path Variations South of Japan: Bimodality as a Self-Sustained Internal Oscillation, J. Phys. Oceanopr., 30, 2124-2137, 2000.

Reynolds, R. W., Smith, T. M., Liu, C., Chelton, D. B., Casey, K. S., and Schlax, M. G.: Daily high-resolution-blended analyses for sea surface temperature, J. Climate, 20, 5473-5496, doi:10.1175/2007JCLI1824.1, 2007.

Ridgway, K. R. and Dunn, J. R.: Mesoscale structure of the mean East Australian Current System and its relationship with topography, Progress Oceanogr., 56, 189-222, doi:10.1016/S00796611(03)00004-1, 2003.

Rintoul, S. R. and Sokolov, S.: Baroclinic transport variability of the Antarctic Circumpolar Current south of Australia (WOCE repeat section SR3), J. Geophys. Res., 106, 2795-2814, 2001.

Rio, M.-H., Schaeffer, P., Moreaux, G., Lemoine, J.-M., and Bronner, E.: A new Mean Dynamic Topography computed over the global ocean from GRACE data, altimetry and in-situ measurements, OceanObs09, 21-25 September 2009, Venice, 2009.

Rivnin, R. B.: Biogenic Carbon Cycling in the Upper Ocean: Effects of Microbial Respiration, Science, 291, 2398-2400, doi:10.1126/science.291.5512.2398, 2001.

Sarmiento, J. and Gruber, N.: Ocean biogeochemical dynamics, Princeton University Press, NJ, 2006.

Schartau, M. and Oschlies, A.: Simultaneous data-based optimization of a 1D-ecosystem model at three locations in the North Atlantic: Part I - Method and parameter estimates, J. Mar. Res., 61, 765-793, 2003.

Schiller, A. and Ridgway, K. R.: Seasonal mixed-layer dynamics in an eddy-resolving ocean circulation model, J. Geophys. Res., in review, 2013.

Schiller, A., Oke, P. R., Brassington, G. B., Entel, M., Fiedler, R., Griffin, D. A., and Mansbridge, J. V.: Eddy-resolving ocean circulation in the Asian-Australian region inferred from an ocean reanalysis effort, Progress Oceanogr., 76, 334-365, doi:10.1016/j.pocean.2008.01.003, 2008.

Schiller, A., Ridgway, K. R., Steinberg, C. R., and Oke, P. R.: Dynamics of three anomalous SST events in the Coral Sea, Geophys. Res. Lett., 36, L06606, doi:10.1029/2008GL036997, 2009.

Schiller, A., Wijffels, S. E., Sprintall, J., Molcard, R., and Oke, P. R.: Pathways of intraseasonal variability in the Indonesian Throughflow region, Dynam. Atmos. Oceans, 50, 174-200, doi:10.1016/j.dynatmoce.2010.02.003, 2010.

Smith, N. R.: The Global Ocean Data Assimilation Experiment, Adv. Space Res., 25, 1089-1098, 2000.

Sun, C., Feng, M., Matear, R., Chamberlain, M., Craig, P., Ridgway, K., and Schiller, A.: Marine downscaling of a future climate scenario for Australian boundary currents, J. Climate, 25, 2947-2962, doi:10.1175/JCLI-D-11-00159.1, 2012.

Sweby: High-resolution schemes using flux limiters for hyperbolic conservation laws, IAM J. Num. Analysis, 21, 995-1011, 1984.

Takahashi, T., Sutherland, S. C., Wanninkhof, R., Sweeney, C., Feely, R. A., Chipman, D. W., Hales, B., Friederich, G., Chavez, F., Sabine, C., Watson, A., Bakker, D. C., Schuster, U., Metzl, N., Yoshikawa-Inoue, H., Ishii, M., Midorikawa, T., Nojiri, Y., Kortzinger, A., Steinhoff, T., Hoppema, M., Olafsson, J., Arnarson, T. S., Tilbrook, B., Johannessen, T., Olsen, A., Bellerby, R., Wong, C., Delille, B., Bates, N., and de Baar, H. J.: Climatological mean and decadal change in surface ocean pCO2, and net sea-air CO2 flux over the global oceans, Deep Sea Res. Part II: Topical Studies in Oceanography, 56, 554-577, doi:10.1016/j.dsr2.2008.12.009, 2009.

Taylor, A. H., Geider, R. J., and Gilbert, F. J. H.: Seasonal and latitudinal dependencies of phytoplankton carbon- to-chlorophyll a ratios: Results of a modelling study, Marine Ecol.-Prog. Ser., 152, 51-66, 1997.

van der Werf, P. M., van Leeuwen, P. J., Ridderinkhof, H., and de Ruijter, W. P.: Comparison between observations and models of the Mozambique Channel transport: Seasonal cycle and eddy frequencies, J. Geophys. Res., 115, C02002, doi:10.1029/2009JC005633, 2010.

van Sebille, E., Johns, W. E., and Beal, L.: Does the vorticity flux from Agulhas rings control the zonal pathway of NADW across 
the South Atlantic?, 117, C05037, doi:10.1029/2011JC007684, 2012.

Wanninkhof, R.: Relationship between wind speed and gas exchange over the ocean, J. Geophys. Res., 97, 7373-7382, 1992.

Waseda, T., Mitsudera, H., Taguchi, B., and Yoshikawa, Y.: On the eddy-Kuroshio interaction: Meander formation process, J. Geophys. Res., 108, 3220, doi:10.1029/2002JC001583, 2003.

Westwood, K., Griffiths, B. F., Webb, J., and Wright, S. W.: Primary production in the Sub-Antarctic and Polar Frontal Zones south of Tasmania, Australia; SAZ-Sense survey, 2007, Deep Sea Res., 58, 21-22, 2011.
Whiteway, T. G.: Australian Bathymetry and Topography Grid, Geoscience Australia Record, 21, 46 pp., 2009.

Yamanaka, Y. and Tajika, E.: The role of vertical fluxes of particulate organic material and calcite in the oceanic carbon cycle: Studies using a ocean biogeochemical general circulation model, Global Biogeochem. Cy., 10, 361-382, 1996. 